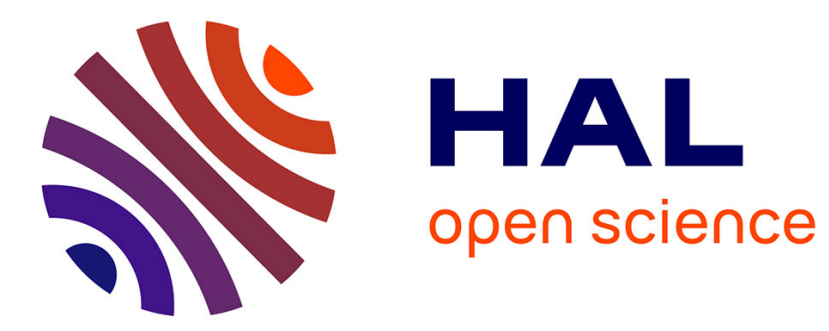

\title{
The GR3D model, a tool to explore the Global Repositioning Dynamicsof Diadromous fish Distribution
}

Thibault Rougier, Hilaire Drouineau, N. Dumoulin, T. Faure, G. Deffuant, Eric Rochard, Patrick Lambert

\section{- To cite this version:}

Thibault Rougier, Hilaire Drouineau, N. Dumoulin, T. Faure, G. Deffuant, et al.. The GR3D model, a tool to explore the Global Repositioning Dynamicsof Diadromous fish Distribution. Ecological Modelling, 2014, 283, pp.31-44. 10.1016/j.ecolmodel.2014.03.019 . hal-01118691

\section{HAL Id: hal-01118691 \\ https://hal.science/hal-01118691}

Submitted on 19 Feb 2015

HAL is a multi-disciplinary open access archive for the deposit and dissemination of scientific research documents, whether they are published or not. The documents may come from teaching and research institutions in France or abroad, or from public or private research centers.
L'archive ouverte pluridisciplinaire HAL, est destinée au dépôt et à la diffusion de documents scientifiques de niveau recherche, publiés ou non, émanant des établissements d'enseignement et de recherche français ou étrangers, des laboratoires publics ou privés. 


\section{The GR3D model, a tool to explore the Global Repositioning Dynamics of}

\section{Diadromous fish Distribution}

3 Thibaud ROUGIER ${ }^{\mathrm{a}}$, Hilaire DROUINEAU ${ }^{\mathrm{a}}$, Nicolas DUMOULIN ${ }^{\mathrm{b}}$, Thierry FAURE ${ }^{\mathrm{b}}$,

4 Guillaume DEFFUANT ${ }^{\mathrm{b}}$, Eric ROCHARD ${ }^{\mathrm{a}}$, Patrick LAMBERT $^{\mathrm{a}}$

5

$6{ }^{a}$ Irstea, EABX, Unité de recherches Ecosystèmes Aquatiques et Changements Globaux, 50

7 avenue de Verdun, Gazinet Cestas, F-33612 Cestas, France

8 thibaud.rougier@irstea.fr

9

10 ' ${ }^{\mathrm{b}}$ Irstea, LISC, Laboratoire d'Ingénierie des Systèmes Complexes, 9 avenue Blaise Pascal 11 CS 20085, 63178 Aubière, France

12

13

14 


\section{ABSTRACT}

16 Within the context of ongoing environmental changes, the life history of diadromous fish

17 represents a real potential for exploring and colonizing new environments due to high 18 potential dispersal abilities. The use of dynamic approaches to assess how these species

19 will respond to climate change is a challenging issue and mechanistic models able to

20 incorporate biological and evolutionary processes are a promising tool. To this end we

21 developed an individual-based model, called GR3D (Global Repositioning Dynamics for

22 Diadromous fish Distribution), combining climatic requirements and population dynamics

23 with an explicit dispersal process to evaluate potential evolution of their distribution area

24 in the context of climatic change. This paper describes thoroughly the model structure and

25 presents an exploratory test case where the repositioning of a virtual allis shad (Alosa alosa

26 L.) population between two river catchments under a scenario of temperature increase was

27 assessed. The global sensitivity analysis showed that landscape structure and parameters

28 related to sea lifespan and to survival at sea were crucial to determine the success of

29 colonization. These results were consistent with the ecology of this species. The integration

30 of climatic factors directly into the processes and the explicit dispersal process make

31 GR3D an original and relevant tool to assess the repositioning dynamics and persistence of

32 diadromous fish facing climate change.

34 Keywords: Climate change, Diadromous fish, Dispersal, Distribution, Individual-based model, Population dynamics 


\section{Introduction}

39 Organisms have two ways to survive to the current major biodiversity threats such as

40 habitat loss and fragmentation, land use changes and more recently climate change. They

41 may adapt to new conditions on site through phenotypic plasticity or evolution, but this

42 might not be possible within the modification ranges or the timescales imposed by climate

43 change (Gienapp et al., 2008; Visser, 2008). Alternatively, species may shift their range,

44 searching for new suitable habitats. Regarding this last option, many studies have now

45 highlighted changes in distribution and community structure in various species (Thomas

46 and Lennon, 1999; Walther et al., 2002; Parmesan and Yohe, 2003; MacKenzie et al.,

47 2007; Nicolas et al., 2011). The success of these relocations or repositioning are contingent

48 upon the dispersal ability of the studied species and the availability of new suitable habitats

49 (Gaston and Blackburn, 2002; Thomas et al., 2004).

Many studies using statistical approaches and species distribution models (Guisan

and Zimmermann, 2000) have analysed the geographical distribution of species or

community with respect to their present environment and used the results to predict

expected distribution areas under climate change scenarios. This type of analysis has been carried out for many taxa such as plants (Midgley et al., 2002; Thuiller, 2003; Zimmermann et al., 2009), reptiles and amphibians (Segurado and Araújo, 2004; Araújo et al., 2006), birds (Huntley et al., 2006), mammals (Thuiller et al., 2006), insects (Heikkinen et al., 2007; Barrows et al., 2008), fish (Buisson, 2009) or diadromous fish (Lassalle, 2008). However, such projections do not consider populations' abilities to adapt to changing environmental conditions (Pulliam, 2000; Guisan and Thuiller, 2005; Jackson et al., 2009). 
63 Franklin, 2010) combining climatic suitability, population dynamics and dispersal

64 (Huntley et al., 2010), few studies have developed mechanistic or semi-mechanistic models to deal with population dynamics and dispersal limitations of species under climate change

66 scenarios (but see Brooker et al., (2007), Keith et al., (2008), Engler and Guisan (2009), Midgley et al., (2010), Hein et al. (2011), Fennell et al., (2012)). Mechanistic models aim to incorporate the processes by which a species disperses through an environment (Merow et al., 2011) and, unlike correlative models, allows one to compare potential and realized distributions (Franklin, 2010; Gallien et al., 2010; Merow et al., 2011). Such models would be a key point for guiding management and conservation of species in a period of rapid environmental changes (Kinnison and Hairston, 2007) especially in fragmented and heterogeneous environments. However, the development of these sorts of models is generally limited by the lack of knowledge about population dynamics and on processes involved in dispersal of the studied species.

The dispersal process is often a critical issue in modelling species movements (Travis et al., 2012). Dispersal is generally defined as (non-returning) movements of individuals away from where they are born, from where they have once reproduced to another breeding site, or between social groups with potentially impacts on gene flow (Clobert et al., 2001; Ronce, 2007; Clobert et al., 2009). It is described as a three-stage process with departure (= emigration), transience (= transfer), and settlement as elementary components (Clobert et al., 2009; Travis et al., 2012). Travis et al., (2012) recently proposed an eco-evolutionary framework for modelling dispersal. However, it is not straightforward to transpose these definitions of dispersal and to define dispersers for diadromous fish according to the diversity and complexity of their life cycles.

Diadromous fishes rely on freshwater, estuarine and marine ecosystems to complete their life cycles (McDowall, 2009; Quinn et al., 2009). Anadromous species achieve most 
of their growth at sea and migrate to freshwater to reproduce either in their natal river

89 (natal homing behavior) or in other rivers (straying) while catadromous species spend most

of their life in freshwaters and migrate to sea in order to reproduce (McDowall, 1988).

91 Diadromous life history strategies have evolved in phylogenetically diverse fish groups

(McDowall, 1997). This original life history characteristic has enabled them to adjust their

distribution to cope with environmental changes (McDowall, 1997; McDowall, 2009) and could allow them to do the same in future changing environments (Lassalle et al., 2009).

Since diadromous species have a real potential to explore and colonize new environments

with a part of their life cycle at sea, a diadromous strategy is an adaptive asset compared to

a holobiotic life history strategy in a context of global change. In this paper, we will only

focus on anadromous species, for which we assume that dispersers are strayed spawners

(i.e. strayers) not making natal homing behavior (i.e. not returning to their natal stream for spawning). However, processes involved in the determination of strayers as well as the behavior of the strayers remain unknown for diadromous species. As dispersal is closely linked to individual behavior, individual-based-models (IBMs) appear to be a promising approach to address the question of dispersal and repositioning dynamics of diadromous fishes. IBMs also offers a flexible and easy way to simulate different behaviors. of IBMs in ecological modelling has increased exponentially (Grimm, 1999) from the seminal works of Huston et al. (1988). Moreover, recent progresses have been made to

108 allow complex IBMs to be better communicated and described (Grimm et al., 2006;

109 Grimm et al., 2010). Many IBMs have already involved fish populations (Van Winkle et 110 al., 1993; Van Winkle et al., 1998; Grimm, 1999; Charles et al., 2008) and more especially

111 diadromous fish such as chinook salmon, Oncorhynchus tshawytscha (Jager et al., 1997),

112 European eel, Anguilla anguilla (Lambert and Rochard, 2007) or more recently Sockeye 
113 Salmon, Onchorhynchus nerka (Reed et al., 2011), brown trout, Salmo trutta (Frank and

114 Baret, 2013) and Atlantic salmon, Salmo salar (Piou and Prévost, 2012, 2013).

115 Furthermore, IBMs are powerful tools to represent biological and habitat mechanisms,

116 individual behavior and variability (Grimm, 1999). They also allow analysing potential

117 climate change effects on natural systems (Reed et al., 2011; Piou and Prévost, 2013) as

118 environmental effects can be directly incorporated in processes. Although complexity is an

119 essential feature of IBMs and can result in unforeseen emergent properties, they may

120 appear over-parameterized if compared to much more parsimonious statistical models.

121 Furthermore, a number of population dynamics parameters are often imprecise and poorly

122 estimated. Hence, it is important to carry out sensitivity analyses (Saltelli, 2004) of this

123 kind of model. Global sensitivity analysis methods are now well known to advance the

124 comprehension and exploration of system modelled (Faivre et al., 2013). In such an

125 analysis, parameters are varied simultaneously allowing identification of interactions by

126 statistical analysis of the simulation results. These methods have already been used in

127 industry (Kleijnen, 1998), ecology (Cariboni et al., 2007) or fishery science (Drouineau et

128 al., 2006; Drouineau et al., 2008; Lehuta et al., 2010).

129 For diadromous species, developing a model combining climatic requirements and

130 population dynamics with explicit dispersal processes is a real challenge and will be a

131 major step forward for guiding management policies. If successful, it could help to

132 determine in which catchment and for which species restoration and restocking actions will

133 be relevant. Moreover, the development of this kind of model for diadromous fish does not

134 appear to be limited by the knowledge of their ecology and their population dynamics

135 which are now well documented (at least for the continental phase) for several species such

136 as Atlantic salmon Salmo salar (Peterson et al., 1977; Bagliniere and Maisse, 1985;

137 Fleming, 1996; Friedland, 1998; Hutchings and Jones, 1998; Forseth et al., 2001; Jonsson 
and Jonsson, 2009; Buoro et al., 2010), European eel Anguilla anguilla (Gatto and Rossi,

139 1979; Vollestad and Jonsson, 1988; De Leo and Gatto, 1995; Dekker, 2000; Lambert,

140 2005; Lambert and Rochard, 2007; Bevacqua et al., 2011), European sturgeon Acipenser

141 sturio (Rochard and Lambert, 2011) or allis shad Alosa alosa (Lambert et al., 2001; Acolas

142 et al., 2006; Lassalle et al., 2008b; Mota and Antunes, 2011; Rougier et al., 2012).

143 In this context, we developed an exploratory simulation model (GR3D: Global

144 Repositioning Dynamics for Diadromous fish Distribution) integrating the whole

145 population dynamics of diadromous fish (reproduction, growth, survival, maturation,

146 downstream and upstream migrations). The GR3D model is individual-based, stochastic

147 and spatially explicit. To test climate change effect on population dynamics, we introduced

148 temperature variations and their effects on demographic traits, such as growth,

149 reproduction and survival. We introduced individual variability through growth, survival,

150 reproduction and migration.

151 Models of high complexity require a substantial exploration phase to avoid

152 misinterpretation of simulation results (Grimm and Railsback, 2005). The more complex a

153 model is, the more its calibration, and the extrapolation and analysis of its results are

154 difficult (Levins, 1966; Caswell and John, 1992). From this consideration, testing a

155 complex model with simple exploratory cases is a reasonable and rational approach (Faivre

156 et al., 2013).

157 Here, we present the GR3D model and show how this generic model may be

158 relevant to study the repositioning dynamics and persistence of diadromous fish in a

159 context of climate change. To illustrate the potential of the model, we applied GR3D in a

160 virtual exploratory study where we assess the repositioning of a virtual anadromous allis

161 shad population between two river catchments under a scenario of temperature increase. 
162 We run the associated sensitivity analysis in order to identify parameters influencing model

163 outputs.

\section{Materials and methods}

\subsection{Model description}

The GR3D model has been developed in Java using the "SimAquaLife" framework

168 (Dumoulin, 2007) which is an individual-based, process-oriented toolkit for aquatic life simulation.

The description of the GR3D model follows the ODD protocol (Overview, Design concepts, Details) for describing individual- and agent-based models (Grimm and

172 Railsback, 2005; Grimm et al., 2006; Grimm et al., 2010).

\subsubsection{Purpose}

The general purpose of GR3D is to evaluate diadromous fish local persistence

175 (defined as the probability for a species to maintain a population in a specific river 176 catchment) (Jager et al., 2013), global persistence (defined as the probability for a species

177 to maintain a population in at least one catchment) and concomitant potential evolution of

178 their distribution area, in the context of climatic change at a European scale combining 179 population dynamics, repositioning behaviors through dispersal processes and climatic requirements.

\subsubsection{State variables and scales}

183 Temporal scales: GR3D simulates a seasonal time step with distinct processes and scheduling in each of these steps.

Entities and spatial scales: Three types of entities compose the GR3D model: one for

186 fish agents and two for environment elements. GR3D is spatially explicit with a continental 
187 compartment and a sea compartment. The continental compartment is split up in "River

188 Basins". Each "River Basin" (RB) is characterized by a name, a position (latitude and

189 longitude at the mouth), a catchment area $\left(\mathrm{km}^{2}\right)$ and seasonal mean water temperatures at

190 the mouth (Table 1).

191 According to the studied species, the sea compartment is either split into "Sea

192 Basins" (SB) associated with one of the river basins, or composed of a unique "sea basin"

193 connected to all the river basins. Each SB is characterized by a name and seasonal mean

194 water temperatures (Table 1).

195 Temperatures in compartments are updated at each time step according to a virtual

196 scenario of water temperature increase or according to a real projection of climate change.

197 Actually, GR3D is designed to work either with virtual environments or real environments

198 such as the Atlantic coast.

199 State variables of diadromous fish individuals: Each diadromous fish is described

200 by an ID, a gender, a maturation stage (mature or immature), an age, a body length, a

201 location (a river basin or a sea basin), a birth place and a number of reproductions.

\subsubsection{Process overview and scheduling}

GR3D is developed to cover the entire life cycle of any diadromous fish species

trying to be the more generic as possible and taking into account the differences between

207 consistent with the life cycle events and processes of any diadromous species

208 (reproduction, growth, survival, downstream migration, maturation, and upstream

209 migration including dispersal). As the present test case deals with an anadromous species

210 (see section 2.2.), we only presented the computational order of life cycle events and 
211 processes in a conceptual diagram for an anadromous species with allis shad as an

212 illustrative case (Fig. 1).

213

214 2.1.4. Design concepts

215 Basic principles: GR3D is a population dynamic model that explicitly includes

216 environmental effects in processes and that incorporates an original dispersal process.

217 During the upstream migration of anadromous fish, we distinguished two kinds of

218 individuals: individuals having a homing behavior (i.e. returning to their natal river to

219 spawn) or having a straying behavior (i.e. not returning to their natal stream). In the

220 absence of information on marine dispersion behavior, we assumed that the choice of a

221 river basin by an individual is the result of three components: 1) a propensity to adopt a

222 homing behavior (characteristic of the species), 2) the accessibility of the river basin, and

223 3) its attractiveness.

224 Interactions: Indirect interactions are included in the reproduction process (see

225 Section 2.1.7.1) through a demographic Allee effect (Allee, 1931; Stephens et al., 1999)

226 and through a density-dependant survival of eggs and larvae.

227 Stochasticity: Demographic stochasticity was incorporated for growth, survival, 228 reproduction and dispersal.

229 Observation: Graphical outputs from "SimAquaLife" interface directly show

230 population-level variables (declared as observable in GR3D) as well as spatial distribution

231 of the individuals. As example, the number of spawners (distinguishing those exhibiting

232 natal homing behavior from those exhibiting straying) and juveniles at each reproduction

233 for each river basin can be recorded as well as the year of the first non-null reproduction

234 and the last year without reproduction. 


\subsubsection{Initialization}

237 The environment, the start and the number of year of simulations, the abundance, the age 238 and the initial distribution of the individuals are initialised according the application case.

239 Population parameters are initialised according to the studied species (see section 2.2.).

\subsubsection{Input}

242 In the current version of GR3D, environmental conditions changed over time via

243 temperature, which changed over space and season. The model is designed to integrate any

244 kind of seasonal temperature temporal series. In a same way, to define the environment, an 245 input file containing river basins characteristics (cf. § 2.1.2) can be used.

\subsubsection{Submodels}

248 GR3D contains 42 parameters, which are listed in Table 2 according to the submodel they

249 are involved in. According to the studied species, their values are obtained either from 250 observations (literature) or are reasonable guessed (i.e. we have only an idea of what would 251 be a realistic value of the parameter) or are calibrated. GR3D is based on six submodels representing fundamental biological processes.

\subsubsection{Reproduction:}

255 Reproduction occurs yearly during the reproduction season (defined as a population 256 parameter, Table 2) in each river basin when spawners are present. We assumed that 257 numbers of recruits $R_{j}$ produced by $S_{j}$ spawners in a spawning basin $j$ follows a Beverton $\&$

258 Holt stock-recruitment relationship of parameters $\alpha_{j}$ and $\beta_{j}$ (BH S-R) (Beverton and 
- We included an Allee effect (Eq. (1)) to take into account difficulties to settle a population with limited numbers of fish in new habitats. Depensation strength is modeled as a function of river basin watershed area through two species specific parameters: $\eta$ a parameter linking the basin watershed area $W A_{j}$ to its carrying capacity (the higher $\eta$ is, the higher the stock level to reach $95 \%$ of the asymptotic recruitment) and $\theta$ which controls the Allee effect strength (a high $\theta$ corresponds to a strong depensation, i.e. the stock level to produce half of the asymptotic recruitment is close to the stock level producing $95 \%$ of the asymptotic recruitment).

$$
R_{j}=\frac{\alpha_{j} S_{j} \frac{1}{1+\mathrm{e}^{\left(-\ln (19) \frac{S_{j}-\eta / \theta \cdot W A_{j}}{\eta \cdot W A_{j}-\eta / \theta \cdot W A_{j}}\right)}}}{\beta_{j}+S_{j} \frac{1}{1+\mathrm{e}^{\left(-\ln (19) \frac{S_{j}-\eta / \theta \cdot W A_{j}}{\eta \cdot W A_{j}-\eta / \theta \cdot W A_{j}}\right)}}}
$$

- By comparison to the traditional BH S-R, we considered that the non-density dependent mortality from egg to recruit (duration $\Delta t_{r e c}$, Table 2) is a function of temperature, consequently parameters $\alpha_{j}$ and $\beta_{j}$ depend on temperature (Eq. (2) and Eq. (3)). Egg survival is optimal ( $s u r v_{\text {optRep }}$,Table 2) at $T_{\text {opt }}$ and there is no recruitment (through a population parameter $\lambda$, Table 2) to take into account resource limitations in small basins (Eq. (5)). dependent mortality of the BH S-R is assumed to be dependent on the basin surface

$$
\begin{gathered}
\alpha_{j}=\frac{b_{j} \mathrm{e}^{-b_{j} \Delta t_{\text {rec }}}}{c_{j}\left(1-\mathrm{e}^{-b_{j} \Delta t_{\text {rec }}}\right)}, \\
\beta_{j}=\frac{b_{j}}{a c_{j}\left(1-\mathrm{e}^{-b_{j} \Delta t_{\text {rec }}}\right)},
\end{gathered}
$$

280 The parameter $a$ is linked to the fecundity of the species (Table 2), 


$$
b_{j}=-\frac{1}{\Delta t_{\text {rec }}} \ln \left[\operatorname{surv} v_{\text {optRep }} \frac{\left(T_{j}-T_{\text {minRep }}\right)\left(T_{j}-T_{\text {maxRep }}\right)}{\left(T_{j}-T_{\text {minRep }}\right)\left(T_{j}-T_{\text {maxRep }}\right)-\left(T_{j}-T_{\text {optRep }}\right)^{2}}\right],
$$

282 and

$$
c_{j}=\frac{\lambda}{\operatorname{Surf}_{j}}
$$

285 We introduce stochasticity in this process by drawing the value of the effective recruitment $R_{E f f, j}$ in a lognormal distribution of standard deviation $\sigma_{\text {rep }}$ around the stock-recruitment relationship (Table 2).

After the reproduction, the population parameter $S p_{s p}$ (Table 2) defined the survival probability of the spawners to take into account the iteroparity of the studied species.

\subsubsection{Downstream migration.}

292 This process occurs at different life stage and season according to the studied species. The

293 age and the season at which this migration occurs are defined as population parameters

294 (Table 2). In this process, individuals migrate from their river location to a determined sea compartment according to the studied species.

\subsubsection{Growth.}

298 The population parameter $L_{i n i}$ determines the initial length of individuals at age $\Delta t_{\text {rec }}$ (i.e. 299 after reproduction).We then use a von Bertalanffy growth function (von Bertalanffy, 1938)

300 derived from Fabens (1965) for modelling of the growth process. Each season, each

301 individual length is updated according to its previous length. In order to introduce

302 individual variability and to avoid negative growth, we use a lognormal distribution to

303 determine the growth increment

$$
\Delta L=\log N\left(\mu_{\Delta L}, \sigma_{\Delta L}\right),
$$


with $\mu_{\Delta L}$ the mean and $\sigma_{\Delta L}$ the standard deviation of the variable's natural logarithm

306 (Table 2). So, $\mu_{\Delta L}$ is expressed

$$
\mu_{\Delta L}=\log \left(\left(L_{\infty}-T L_{t}\right) \times\left(1-\exp ^{-\kappa \Delta t}\right)\right)-\frac{\sigma_{\Delta L}^{2}}{2}
$$

where $T L_{t}$ is the total length of a fish at time unit $t, L_{\infty}$ is a population parameter corresponding to the asymptotic length of fish (Table 2) and $\kappa$ is the growth coefficient.

311 (Rosso et al., 1995) is used to correlate the growth coefficient to temperature and introduce

312 seasonal variability (Mallet et al., 1999; Dion and Hughes, 2004; Kielbassa et al., 2010;

313 Bal et al., 2011). According to this function, the growth coefficient $\kappa$ and temperature are

314 linked by a bell-shaped relationship. In fact, $\kappa$ is equal to 0 if the temperature is lower or

315 equal to the minimal growth temperature $T_{\text {minGrow }}$; it increases with temperature up to an

316 optimum $\kappa_{\text {optGrow }}$ at the optimal growth temperature $T_{\text {optGrow }}$. If temperature continues to

317 increase, the growth coefficient $\kappa$ rapidly decreases down to 0 at the maximal growth

318 temperature $T_{\text {maxGrow }}$. The relationship is expressed

$$
\kappa=\kappa_{\text {optGrow }} \frac{\left(T-T_{\text {minGrow }}\right)\left(T-T_{\text {maxGrow }}\right)}{\left(T-T_{\text {minGrow }}\right)\left(T-T_{\text {maxGrow }}\right)-\left(T-T_{\text {optGrow }}\right)^{2}} .
$$

Parameters $T_{\text {minGrow }}, T_{\text {optGrow }}, T_{\operatorname{maxGrow}}$ and $\kappa_{\text {optGrow }}$ are population parameters (Table 2).

\subsubsection{Survival.}

325 At each time step, the survival of each individual is assessed depending on its location and stage. 
327 For individuals at sea, the seasonal survival probability, $S p_{\text {sea }}$, is calculated using the

328 annual mortality coefficient at sea, $Z_{\text {sea }}$, defined as a population parameter (Table 2 ) and a

329 survival equation

$$
S p_{\text {sea }}=\exp ^{-Z_{\text {sea }} \times \Delta t_{\text {season }}},
$$

331 where $\Delta t_{\text {season }}$ is the duration of a season (i.e. 0.25 year $^{-1}$ ). We assumed that $Z_{\text {sea }}$

332 incorporates all sources of individual mortality at sea.

333 For individuals in river, the seasonal survival probability, $S p_{r i v}$, is calculated using two

334 annual mortality coefficients $M_{r i v}$ (natural mortality coefficient) and $H_{r i v}$ (human-induced

335 mortality coefficient) defined as population parameters (Table 2) and a survival equation

$$
S p_{r i v}=\exp ^{-\left(M_{r i v}+H_{r i v}\right) \times \Delta t_{\text {season }}} .
$$

337 The natural mortality coefficient $M_{r i v}$ is assumed to be dependent on the river temperature

$338 T_{j}$ and was computed as follows

$$
M_{r i v}=\frac{-\ln \left(\operatorname{surv}{ }_{\text {optRiv }} \frac{\left(T_{j}-T_{\text {minSurvRiv }}\right)\left(T_{j}-T_{\text {maxSurvRiv }}\right)}{\left(T_{j}-T_{\text {minSurvRiv }}\right)\left(T_{j}-T_{\text {maxSurvRiv }}\right)-\left(T_{j}-T_{\text {optsurvRiv }}\right)^{2}}\right)}{\Delta t_{\text {season }}},
$$

340 where $T_{\text {minSurvRiv }}, T_{\text {optSurvRiv }}, T_{\text {maxSurviv }}$ and surv $v_{\text {optRiv }}$ were population parameters (Table 2).

341 We assumed that the other mortality coefficient $H_{r i v}$ incorporates the other sources of mortality in river (fishery, pollution, dams...).

\subsubsection{Maturation.}

345 In the current version of GR3D, individual maturation is not explicit and did not involve energy allocation processes. An individual becomes mature as soon as its length reached

347 the length at first maturity $L_{\text {mat }}$ (defined as a population parameter, Table 2) and its maturation stage changed from immature to mature. 


\subsubsection{Upstream migration.}

351 This submodel is essential in the model since we assumed that dispersal is linked to this migration. This process occurs at different life stages and seasons depending on the studied species. The age and the season at which the downstream migration occurs are defined as population parameters (Table 2). It has been designed as a three-stage process with emigration, movement and settlement phases.

1. The emigration phase: in this phase, individuals have a probability to adopt a homing ( $\left.p_{\text {hom }}\right)$ or a straying behavior $\left(1-p_{\text {hom }}\right)$ which is assumed to be a characteristic of the species. $p_{h o m}$ is defined as a population parameter (Table 2).

2. The movement phase: Individuals that do not become strayers simply migrate in their natal river (homing behavior). For strayers, the probability to migrate in each river basin is assumed to be a function of its accessibility and its attractiveness. We assumed that accessibility depends on the dispersal distance $D_{j-\text { birthPlace }_{i}}$ between basin $j$ and the birth

364 place of an individual $i$, and on the total length $T L_{i}$ of the individual $i$. The basin 365 attractiveness is assumed to be a function of its watershed area $W A_{j}$ as a proxy of the river 366 flow. Then, the "weight" of each basin relative to an individual $i$ is computed using a logit 367 function

$$
\begin{aligned}
\operatorname{logit}\left(w_{i}^{j}\right) & =\alpha_{\text {const }}+\alpha_{\text {dist }}\left(\frac{D_{j-\text { birthPlace }}-\overline{D_{j-\text { birthPlace }}}}{\sigma_{j-\text { birthPlace }}}\right), \\
& +\alpha_{T L}\left(\frac{T L_{i}-\overline{T L}}{\sigma_{T L}}\right)+\alpha_{W A}\left(\frac{W A_{j}-\overline{W A}}{\sigma_{W A}}\right),
\end{aligned}
$$

369 where $\alpha_{\text {const }}, \alpha_{\text {dist }}, \alpha_{T L}$ and $\alpha_{W A}$ are four population parameters (Table 2). In order to have 
371 function and we defined $\overline{D_{j-\text { birthPlace }}}, \sigma_{j \text {-birthPlace }}, \overline{T L}, \sigma_{T L}, \overline{W A}$ and $\sigma_{W A}$ as population

372

373 We assumed that individuals may also not find any basin so we introduce a virtual "death

374 basin" with a fixed weight $w^{\text {deathBasin }}$. Then $w_{i}^{j}$ are standardized so that their sum equals 1 ,

375 providing probabilities to choose each river basin (including death basin). The choice is

376 then modelled by a simple multinomial process.

377 3. The settlement phase: Individuals enter in the selected destination, survive if conditions 378 are suitable and reproduce if they find mating requirements.

379

380

381

382

383

384

385

386

387

388

389

390

391

393

394

\subsection{The test case}

\subsubsection{Description of the studies species}

Allis shad (Alosa alosa L.) is an anadromous clupeid spawning in the higher middle watercourse of rivers. Fish migrate to sea during their first year, where they grow and return to freshwater to spawn at between 3 and 6 years (Bagliniere and Elie, 2000; Baglinière et al., 2003). Currently, populations of allis shad exist along the northeastern Atlantic coasts in some large rivers of France (Loire, Gironde-Garonne-Dordogne, and Adour) and Portugal (Minho and Lima) (Lassalle et al., 2008b) and despite some protective measures, this species appears to have been in serious decline for a number of years (Limburg and Waldman, 2009; Rougier et al., 2012). Biology and ecology of allis shad have therefore received a great deal of attention in the last 30 years (MennessonBoisneau and Boisneau, 1990; Prouzet et al., 1994; Bagliniere and Elie, 2000; Acolas et al., 2004; Acolas et al., 2006) and several studies also dealt with its population dynamics (Martin Vandembulcke, 1999; Lambert et al., 2001; Rougier et al., 2012). 


\subsubsection{Environment, time and initialization}

396 An environment with two rivers basins (RB1 and RB2) and two sea basins (SB1 and SB2)

397 highly associated to the river basins (i.e. RB1 with SB1 and RB2 with SB2) was used for

398 the test case. Our experiment mimics a situation where temperature increase opened the

399 opportunity for a stable allis shad population in RB1 to expand into a new suitable river

400 RB2. Two environmental parameters were defined to determine the initial configuration of

401 the environment: WA_RB2 corresponding to the watershed area of the uninhabited river basin RB2 and intDist describing the distance between RB1 and RB2. the first fifty years of simulation, a virtual population of allis shad was created in RB1 by introducing there 500000 juveniles at the first time step. From the year 50 to the year 150 , we introduced in the two basins a linear water temperature increase of $3^{\circ} \mathrm{C}$ in 100 years (i.e. water temperature increase by $0.0075^{\circ} \mathrm{C}$ at each time step) and $\mathrm{RB} 2$ becomes suitable for allis shad reproduction. At the end of the temperature increase, only RB2 is suitable for allis shad for the last 50 years of simulations. Temperatures in RB1 and RB2 were

410 initialized with the same values except for the spring temperature as we used it to control

411 the suitability of each river during the simulation. In order to work with realistic values, we

412 used daily estimates of Gironde estuarine water temperature $\left({ }^{\circ} \mathrm{C}\right)$ provided by EDF

413 (Electricité De France) between 1991 and 2009 to initialize the winter, summer and 414 autumn temperatures in RB1 and RB2 as the Gironde basin is located at the center of the 415 allis shad distribution area (Baglinière, 2000; Lassalle, 2008). Spring temperature of RB1 416 was set to $3^{\circ} \mathrm{C}$ below $T_{\text {maxSurviv }}$ and set to $T_{\text {minRep }}$ in RB2. The watershed area of RB1 was 417 set to $40000 \mathrm{~km}^{2}$. The environmental parameters WA_RB2 and intDist were included in the 418 global sensitivity analysis to assess the influence of the environment configuration on 419 model outputs (see section 2.2.4.). 

mean between $12^{\circ} \mathrm{C}$ and the seasonal mean water temperatures of $\mathrm{RB} 1$ and $\mathrm{RB} 2$, respectively. variables were initialized as follows for each new individual: gender was assigned according to a sex ratio of $1: 1$; stage was set to "immature", the number of reproduction was set to 0; and the birth place was set according to their birth location.

\subsubsection{Model parameterisation}

429 For this test case with allis shad, 20 population dynamics parameters were obtained from

430 literature, 18 were parameterized as reasonable guesses (based upon expertise), and 4 were estimated using off-line calibration (Table 2). the population dynamics of allis shad in the Gironde basin for the parameterization of the

434 reproduction process (i.e. parameter $\eta, \theta$, surv $v_{\text {optRep }}$ and $\lambda$ of the BH S-R relationship, 435 Table 2) and used their estimates of $\alpha_{\text {Gironde }}, \beta_{\text {Gironde }}$ and $\eta$. We assumed that the 436 recruitment was a number of juveniles in estuary and set $\Delta t_{\text {rec }}$ to 0.33 year (4 months) as it 437 corresponds to the average duration of the juvenile downstream migration towards the sea 438 (Lochet et al., 2008).

439 We assumed dispersal of allis shad was only dependant of the distance between the 440 suitable habitats. Hence, $\alpha_{T L}$ and $\alpha_{W A}$ were set to 0 . We set $\sigma_{j \text {-birthPlace }}$ to $978 \mathrm{~km}$ (using 441 the EuroDiad 2.0 database of European river basins from Lassalle (2008)). We set $442 \overline{D_{j-\text { birthPlace }}}$ to $300 \mathrm{~km}$ as we assumed that this value was close to the maximal distance of 443 dispersal for allis shad. Then we assumed a weight of 0.95 and 0.05 for a basin located at a 
444 distance of $10 \mathrm{~km}$ and $300 \mathrm{~km}$ respectively. In consequence, $\alpha_{\text {const }}$ and $\alpha_{\text {dist }}$ were set to $445 \quad-2.9$ and 19.7 respectively (Table 2).

\subsubsection{Sensitivity analysis}

448 For these simulations, we mainly focused on the success of the colonization of RB2.

449 Hence, we recorded the following 2 output variables: (i) $f_{s}$ was a qualitative variable 450 describing the final state of RB2 using the value of the coefficient of variation $(\mathrm{CV})$ of the 451 recruitment in $\mathrm{RB} 2$ during the last ten years of simulations, i.e. that it took either the value

4520 if the $\mathrm{CV}$ was null, or the value 1 if the $\mathrm{CV}$ was higher than a threshold arbitrarily set to $5 \%$, or the value 2 if the $\mathrm{CV}$ was positive and lower than the threshold; (ii) $\mathrm{mlr}$ was the mean of the recruitment in RB2 during the last ten years of simulations.

We defined two variables using the $f_{s}$ output variable. $f_{S} P$ indicated the presence/absence of fish in RB2 (i.e. $f_{s}=0$ for absence and $f_{s}>0$ for presence).

457 Considering only positive values of $f s$, we defined $f_{S} S$ as a variable describing a kind of stability of the RB2 population (i.e. relatively unstable for $f_{s}=1$ because it means that there is high variation in the recruitment values in the ten last year of simulation, and stable

460 for $f_{s}=2$ because it means that recruitment values are stable in the ten last years of

461 simulation). Hence, we used these two variables to analyze the influence of parameters on 462 both the presence/absence of fish in RB2 and on the stability of the population in RB2. mlr was a metric indicating the abundance of fish in RB2. As the null values described absence of fish in RB2, we only used positive values of $m l r$ to analyze the influence of parameters on abundance in RB2.

In order to screen non-influential and influential parameters on GR3D model outputs, we conducted a global sensitivity analyses by varying both the model and the 
the GR3D model to incorporate in the sensitivity analysis and we added 2 environmental

470 parameters in the analysis (WA_RB2 the watershed area of RB2 and intDist the distance

471 between RB1 and RB2; Table 3). Considering a maximal range of variation of $20 \%$ often

472 used in sensitivity analysis (Drouineau et al., 2006; Lehuta et al., 2010), we set a low and a

473 high value for each population parameter based on our own expertise and knowledge of

474 allis shad population dynamics (Table 3). Concerning environmental parameters, we

475 considered three modalities for $W A \_R B 2$ and four for intDist (Table 3). As a complete

476 design would have taken too much time since it would involve more than 12 million

477 simulations without replicates $\left(2^{20} \times 3 \times 4\right)$, we first used an experimental design to

478 identify the most influential parameters on model outputs. Regarding the number of factors

479 and modalities, the most appropriate experimental design are D-optimal designs

480 (Drouineau et al., 2006; Faivre et al., 2013). In this type of design, the estimations of the

481 effects are partially correlated (i.e. that contrary to factorial design, confusion between

482 effects estimates may exist, but an algorithm is used to find the set of experiments),

483 maximizing the determinant of the information matrix ( $\mathrm{XX}^{\prime}$ with $\mathrm{X}$, the matrix of the

484 different combinations of modalities for each experiment) of the design, equivalent to

485 maximizing the efficiency of the estimation (Droesbeke et al., 1997; Drouineau et al.,

486 2006). We use the AlgDesign $\mathrm{R}$ package (Wheeler, 2011) to generate our D-Optimal

487 design and, finally, the resulting experimental design consisted of 1300 simulations that we

488 replicated 10 times. Only main effects were estimated with this design using a logistic

489 regression model for $f_{s} P$ and $f_{s} S$ and analysis of variance (ANOVA) for $m l r$. For each

490 model output response $y$, first order indices $(S I)$ of a parameter $x_{i}$ measuring the importance

491 of the deviance (or variance for $m l r$ output) of the $y$ mean conditionally on factor $x_{i}$, were

492 considered as a sensitivity index (Saltelli, 2004; Saltelli et al., 2008; Faivre et al., 2013)

493 and were calculated as follows 


$$
\operatorname{SI}\left(x_{i}\right)=\frac{\operatorname{Dev}\left[E\left(y \mid x_{i}\right)\right]}{\operatorname{Dev}(y)} .
$$

495 Focusing on the ten highest SI of the 3 model outputs, we selected the most influential

496 parameters. For computation time reasons, we were not able to select more than 13

497 parameters. Then with the most influential selected parameters, we used a complete

498 sampling with 10 replicates in order to estimate main effects and first order interactions

499 effects on the sensitivity of model outputs. We used the same models as those used with

500 the experimental design to estimate SI and global sensitivity indices (TSI). TSI, that

501 measured the mean of the $y$ deviance (or variance for $m l r$ output) on the uncertain

502 parameters different from $x_{i}$ (Saltelli, 2004; Saltelli et al., 2008; Faivre et al., 2013), were

503 calculated for each parameter as follows

$$
\operatorname{TSI}\left(x_{i}\right)=\frac{E\left[\operatorname{Dev}\left(y \mid x_{j}, j \neq i\right)\right]}{\operatorname{Dev}(y)} .
$$

TSI corresponds also to a measure of the sum of the main effect of a parameter $x_{i}$ and the

506 effects of interactions of this parameter with all the other uncertain parameters (Saltelli,

but TSI is higher than SI as it includes interaction effects. Estimating the impact of first order interaction was necessary to assess the combined effect of uncertainties on two

510 parameters, which may be different from the sum of the main effects of the two

511 parameters. We expressed SI and TSI in percentage and we assumed the more distant from

5120 they were, the more impact they have on model results.

513 Statistical analyses of model outputs were carried out using R (R Core Team,

514 2013). To run all our simulations of the sensitivity analysis, we used OpenMOLE which is

515 a workflow engine specifically tailored for the distributed exploration of simulation models

516 (Reuillon et al., 2013). 


\section{Results}

519 We present in Fig 2 an illustrative example of model output where we followed the

520 dynamics over time in RB1 and RB2 of the recruitment for a same set of parameters by

521 just varying the value of the distance between RB1 and RB2.

\subsection{Selection of the most influential parameters}

523 Among the 13000 simulations with the D-Optimal design, we observed failure of

524 colonization of RB2 in $48 \%$ of simulations (i.e. $f s=0$ ). Thirteen percent of simulations led to an unstable population (i.e. $f s=1$ ) and $39 \%$ led to stable situations in RB2 (i.e. $f s=2$ ). The logistic regression applied to $f_{s} P$ and $f_{s} S$ explained $78 \%$ and $70 \%$ of the null deviance respectively and the analysis of variance of $m l r$ explained $60 \%$ of the null variance (Table 4). Focusing on the ten highest $S I$ of the three model outputs, we identified 13 different

529 parameters meaning that model outputs are relatively sensitive to the same parameter (Fig.

5303 3). It was especially true for $f_{s} P$ and $f_{s} S$ which were very sensitive to the distance between

531 RB1 and RB2 that explained around $50 \%$ of the deviance for these two variables (Fig. 3).

532 These two variables were also sensitive to parameters of the growth $\left(\kappa_{\text {optGrow }}\right)$, maturation

$533\left(L_{m a t}\right)$, and survival processes $\left(Z_{\text {sea }}\right)$ which are highly linked to the duration of the 534 individual life at sea (Fig. 3). So, the success of colonization and the stability of the 535 population were, not surprisingly, negatively linked to intDist, but also to parameters that increased the duration of the life at sea. $m l r$ was mainly sensitive to the watershed area of

537 RB2 (Fig. 3) with a positive correlation between $m l r$ and $W A \_R B 2$ as this parameter is 538 involved in the reproduction process to determine the production capacity of RB2. $m l r$ was 539 also sensitive to the other parameters of the reproduction process (Surv ${ }_{\text {optRep }}, \lambda$ and $T_{\text {optRep }}$ ) 540 and to the environmental parameter intDist. To select the most influential parameters, we

541 kept 12 of the 13 parameters identified in the ten highest SI of the three model outputs.

542 Actually, as the outputs were not very sensitive to $T_{\operatorname{maxSurv} i v}$ which was a parameter used to 
543 control the suitability of RB1 in our test case, we did not select this parameter and rather

544 selected the parameter $w^{\text {deathBasin }}$ involved in dispersal. Among the 13 selected parameters,

545 four concerned the reproduction process, two concerned the growth, survival and upstream

546 migration (i.e. dispersal) processes, one concerned the maturation process and the last two

547 were environmental parameters (Table 3). Consequently, in the second step of the 548 sensitivity analysis, the complete sampling consisted in 24576 simulations that we 549 replicated 10 times.

\section{3.2. Analysis of interaction effects}

551 Among the 245760 simulations, we observed $49 \%$ of unsuccessful colonization, $11 \%$ of

552 simulations led to an unstable population in RB2 and $40 \%$ led to a stable situation.

553 Although we considered fewer parameters than with the D-Optimal design, the explained

554 deviance and variance of the outputs analysis increased in this second step of the

555 sensitivity analysis because we took first order interactions effects into account. We

556 explained $90 \%$ and $85 \%$ of the deviance for $f_{S} P$ and $f_{S} S$ respectively and $79 \%$ of the

557 variance for $m l r$ (Table 4). The output variables were globally sensitive to the same 558 parameters than those observed with the D-Optimal design (Fig. 4). This sensitivity 559 analysis confirmed that the model outputs $f_{S} P$ and $f_{S} S$ were particularly sensitive to the 560 environmental parameter intDist and to parameters increasing the duration of the life at sea

$561\left(\kappa_{\text {optGrow }}, L_{m a t}\right.$, and $\left.Z_{\text {sea }}\right)$ and that $m l r$ was sensitive to the two environmental parameters and

562 to parameters of the reproduction process. Additionally, we observed a great importance of

563 the interaction effects for two parameters: the homing probability $p_{\text {hom }}$ and the parameter

$564 \theta$ of the reproduction process which is linked to the strengh of the Allee effect (Fig. 4).

565 This was especially true for the $f s S$ output where the main effect of the homing probability 566 and the parameter $\theta$ were very low $(0.02 \%$ and $0.03 \%$ respectively) while the interaction

567 effects of these factors with other parameters explained $6.3 \%$ and $4.9 \%$ of the null 
deviance respectively (Fig. 4). Interaction effects of the homing probability were

569 particularly high with the distance between RB1 and RB2 and the optimal growth

570 coefficient $\kappa_{\text {optGrow }}$. For the parameter $\theta$, interaction effects were high with the length at

571 first maturity, the optimal growth coefficient and the annual mortality coefficient at sea.

572 We also observed a high interaction between the weight of the death basin and the distance

573 between RB1 and RB2 to explain the stability of the population in RB2.

574 To summarize, the success and the stability of the colonization of RB2 are very

575 sensitive to the landscape structure represented through the distance between RB1 and RB2

576 and to parameters related to the duration of the life at sea and the survival condition in this

577 compartment. Interaction effects mainly highlighted that the role of the homing and the

578 Allee effect should be considered with attention. Concerning the abundance of the

579 recruitment in $\mathrm{RB} 2$, it is sensitive to parameters of the reproduction process and to the

580 watershed area of RB2.

\section{4. Discussion}

583 We developed, implemented and tested an individual-based model combining population

584 dynamics, dispersal and temperature requirements. GR3D has been designed to assess the

585 persistence of diadromous fish and the evolution of their distribution area in a context of

586 global warming. To our knowledge, this is the first attempt to incorporate dispersal

587 abilities of diadromous fish within a dynamic approach at the scale of their distribution

588 range. This article focuses on the individual-based model description and its exploration

589 with a basic virtual test case. We deliberately chose to run our simulations in a simple,

590 virtual environment in order to clearly disentangle the effect of the environment and the

591 effect of uncertainties in population dynamics on model outputs using a global sensitivity

592 analysis. We demonstrated the sensitivity of the outputs to some key population dynamics 
parameters and to environmental parameters which were consistent with our knowledge of

594 this species. We considered our results are satisfactory enough to address more precisely, in further studies, the issue of allis shad persistence in a context of global change at the real and can represent an integrative tool to study persistence of diadromous fish whose population dynamics is well documented. After discussing the innovations and the

599 structure of the model, we come back to the understandings brought by our test case and its associated sensitivity analysis.

601

\subsection{Innovations and model structure}

603 The GR3D model incorporates an explicit dynamic model of diadromous fish dispersal 604 process at large scale. This is particularly relevant in a context of climate change since Brooker et al. (2007) has demonstrated that dispersal ability of individuals interacts with

606 the rate of climate change to determine range shifting dynamics. To model dispersal in 607 GR3D, we took both landscape structure and individual dispersal abilities into account. We 608 defined a generic accessibility model for available habitats (i.e. river basins) that depends 609 on the dispersal distance and the size of the individuals (as it represents a proxy of their 610 swimming capacities). Dispersal distance has already been recognized as an important

611 factor in dispersal processes and is often represented through dispersal kernels in dispersal 612 modelling approaches (Chesson and Lee, 2005; Slone, 2011; Bocedi et al., 2012).

613 Moreover the individual size has been recognized as closely linked to dispersal potential of 614 individuals with potential impacts on species' range shifts through phenotype dependent 615 dispersal processes (McCauley and Mabry, 2011). Furthermore, incorporating the size of 616 individuals in a context of climate change is relevant as shifts in body size and its 617 consequences in dispersal (and also in a lot of other life history parameters) have been 
618 identified as the third major response to climate change (Gardner et al., 2011). In our

619 dispersal process, we also modelled the attractiveness of the available habitats as a function

620 of their watershed area as we assumed it was a proxy of the river flow. River flow has

621 already been showed as being the vector of attractive factors for diadromous species such

622 as larval pheromone by the sea lamprey (Petromyzon marinus) (Vrieze and Sorensen,

623 2001) or natural stream odor by salmon (Barinaga, 1999). The function we used for

624 dispersal modelling can then be parameterized and calibrated according to the studied

625 species and the knowledge of its population dynamics. This process has been designed in

626 order to integrate easily other effects that could potentially influence dispersal of a species.

627 Moreover, although our test case dealt with an anadromous species, the GR3D

628 model could also be adapted to catadromous species assuming for these species that

629 dispersers are strayed juveniles that do not use the same growing area (river catchment or

630 estuary) than their parents and have to choose consequently another river basin for their

631 freshwater life. However, the high heterogeneity of diadromous fish species life histories

632 (McDowall, 1988; McDowall, 1997) imply that further specific and local adjustments

633 might be required for different species. For instance, in its current version, GR3D is not

634 able to deal with the diversity and complexity of Atlantic salmon life cycle. A large

635 amount of literature is available for this species describing its population dynamics in

636 many catchments (Mangel, 1994; Rivot et al., 2004; Reed et al., 2011). Recently, Piou and

637 Prevost (2012) developed and parameterized IBASAM, a complex individual-based model

638 to simulate population dynamics of Atlantic salmon in the Scorff River (Brittany, France).

639 Despite the high complexity of this model, it does not incorporate all phenotypes of

640 Atlantic salmon life histories and further developments would also be needed according to

641 the Atlantic salmon population studies. The IBASAM model, described as a tool for the

642 investigation of potential climate change effects on Atlantic salmon population structure, 
643 did not consider individual dispersal and so potential modification of distribution range in

644 response to environmental change. Consequently, the GR3D and IBASAM models might

645 be complementary dynamic approaches in order to study Atlantic salmon response to

646 climate change.

647 As GR3D is a complex model integrating numerous parameters, our study dealt

648 also with the question of the degree of complexity that should be incorporated in modeling

649 approach as the more the complexity is high in a model, the more the model is able to

650 reproduce the observed reality but the more it is difficult to calibrate, to extrapolate and to

651 analyze the model results (Levins, 1966; Caswell and John, 1992). Some authors consider

652 that simple models are the best way to lead to generality in ecology (Holling, 1966) while

653 other authors argue that this point of view may be an obstacle to the progress of ecological

654 research and demonstrate that in some cases at least, complex models are desirable,

655 general, and can be linked with simple models (Lassalle, 2008; Evans et al., 2013). In the

656 GR3D model, several simplifications were made in the structure of the model. First, in its

657 current version, GR3D does not deal with genetic and evolution issues although future

658 works have already been envisaged in this aim. Second, we did not represent explicit

659 movements of individuals within compartments (e.g. with a random walk process

660 (O'Sullivan and Perry, 2009)) and we assumed homogeneous conditions within a

661 compartment. Third, despite the expected impact of climate change on precipitation and

662 therefore river discharge, we did not incorporate the effect of discharge on population

663 dynamics processes as we were not able to link the effect of this parameter on life history

664 traits, largely because models linking precipitation to river flow are complex and focus

665 mostly at local scales (Milly et al., 2005; Qi et al., 2009; Beyene et al., 2010). Finally,

666 GR3D is a generic mono-species model and thus does not take into account potential

667 interactions between or among species. There are thus opportunities for further 
668 improvements of the model. However, these improvements would undoubtedly lead to a

669 significant increase in model complexity and consequently of the computation time. In our 670 opinion, our mechanistic representation is realistic enough to address the issue of

671 diadromous fish dispersal and their persistence under climate change at a large scale.

672 Consequently, GR3D appears as a great step forward in management of diadromous fish

673 species. It could be used as an integrative tool to assess potential impact of climate change

674 on endangered diadromous fish species. For instance, we might be able to identify for an

675 endangered population if demographic rescue from neighboring populations will be likely

676 or if restocking program would be relevant and necessary (Seddon et al., 2009; Loss et al.,

677 2011). The GR3D model is able to generate predictions of change in the distribution of 678 species but also predictions of population abundances under defined climate change 679 scenario.

680

681

\subsection{Model parameterization and sensitivity}

682 GR3D was parameterized to reproduce dispersal and population dynamics of a virtual allis 683 shad population between two river catchments in a context of temperature increase. After 68450 years of simulations to initialise an abundant and stable population in RB1, temperature started to increase and RB2 became gradually suitable while suitability of RB1 gradually decreases. This scenario was a way to mimic a situation where a population threatened by

687 temperature warming had an opportunity to colonize a new suitable habitat. Consequently 688 for analyzing model results, we mainly focused on the colonization of previously 689 uninhabited river basin RB2. With a more complex environment, it would have been 690 difficult to clearly disentangle the effect of the environment and the effect of uncertainties 691 in population dynamics on model outcomes. We chose therefore this simple test case. 
GR3D is a complex model incorporating a high number of parameters.

693 Consequently, several analyses were necessary to further understand the relative role of

694 different parameters in the model outputs. Such analyses are essential for complex models

695 to avoid misinterpretation of simulation results (Grimm and Railsback, 2005). From this

696 consideration, the fast computation time of the GR3D model is a real advantage. Actually,

697 in our simple test case, the model dealt with millions of individuals but each simulation of

698200 years took less than one second with a mean duration of simulations around 0.3

699 second. We tested the model with more complex virtual environment (e.g. with 25 river

700 basins) and the duration of simulation was always below one minute.

In the test case, we assumed that dispersal depended only on the dispersal distance.

702 We did not incorporate an effect of the individual length as we considered only one

703 population and as the length of allis shad spawners (i.e. potential dispersers for this species) has always been observed as relatively homogeneous within a population (Bagliniere and Elie, 2000). We also ignored the effect of the watershed area in the dispersal function, as only one river was available for dispersers.

Analyzing the success of the colonization of RB2 and the stability of the population

708 in RB2, our sensitivity analyses showed the importance of dispersal distance and of

709 parameters related to the duration of the life at sea $\left(\kappa_{\text {optGrow }}, L_{m a t}\right)$ and the survival condition

710 in this compartment $\left(Z_{\text {sea }}\right)$. These results were consistent with our expectation and

711 reproduced the expected dynamics of the model. We populated the environment initially in

712 order to have an abundant and stable population in RB1. Consequently, a high number of

713 dispersers were able to colonize the uninhabited river and were only limited by the distance

714 they have to cross. The duration of the life at sea is highly linked to the resilience of 715 diadromous species (i.e. the more the individuals stay at sea, the more the mortality of 716 individuals is high and the resilience of the studied species is low) and so unsurprisingly 
717 influences dispersal and stability of population as well as the survival conditions at sea.

718 The analysis of interactions effects showed the importance of the homing $\left(p_{\text {hom }}\right)$ and of the

719 Allee effect (parameter $\theta$ ). As the probability of homing determines the number of

720 dispersers, it was also not surprising to obtain a high interaction effect with the dispersal

721 distance. In a same way, we introduced an Allee effect in the reproduction dynamics in

722 order to take into account potential difficulties to establish a population in an uninhabited

723 river basin such as mate limitation and reproductive facilitation problems or a decrease of

724 juvenile mortality with decreasing stock size (Berec et al., 2007). It explains consequently

725 the high effect of the interactions of this parameter. Concerning the abundance of the RB2

726 population, the most influential parameters were, as expected, parameters linked to the

727 success of the reproduction. Actually, parameters surv optRep $_{2} \lambda$ and $T_{\text {optRep }}$ defined the

728 survival of individuals between egg and recruit stages and the watershed area of RB2 were

729 directly linked to its production capacity.

730 Furthermore, model outcomes were not very sensitive to thermal parameters. This

731 result might be explained by a high thermal tolerance of the allis shad species and by the

732 use of the Gironde basin temperature to initialize temperature of RB1 and RB2 (except the

733 spring temperature that we modified to control the suitability of the two rivers). The

734 Gironde system is located in the middle of the allis shad distribution range and, although

735 the Gironde allis shad population is endangered, this might not be because of an

736 environmental change (Rougier et al., 2012).

737 The results of this test case are a good way to illustrate the dynamics included in the

738 GR3D model. This step was necessary before applying GR3D to a more complex case

739 study to avoid misinterpretation on the model results. Simulation results of the GR3D

740 model might also be compared with results of a species distribution model applied to the

741 same species by Lassalle (2008). We could quantify the divergence in prediction of future 
742 potential distribution between static and dynamic approaches as has already be done for

743 two virtual plant species by Engler and Guisan (2009), who showed significant differences

744 between the two kind of approach. Recently, Estes et al. (2013) also compared mechanistic

745 and empirical model projections for the suitability of a crop species and concluded that

746 both approaches might be complementary. Lassalle et al. (2008a) described the 1900

747 observed distribution of European diadromous fish species. Using this 1900 distribution in

748 GR3D as an input defining the initial distribution of individuals, and then, simulate

749 population dynamics from 1900 to today might be a way to validate the GR3D model. We

750 could thus compare projected distributions of GR3D simulation results with the current

751 distribution of European diadromous fish species to analyze whether species have

752 responded in the way that the GR3D model suggests (Kerr and Dobrowski, 2013).

753

754 Acknowledgments

755 We wish to thank G. Lassalle, F. Daverat and N. Séon-Massin for fruitful discussions

756 helping in developing the model. Sincere thanks are due to Karin Limburg for English

757 corrections and some valuable comments and suggestions. This study was supported by

758 grants from the French National Research Institute of Science and Technology for

759 Environment and Agriculture (Irstea) and the French National Agency for Water and

760 Aquatic Environments (ONEMA).

761

762 References

763 Acolas, M.L., Bégout Anras, M.L., Véron, V., Jourdan, H., Sabatié, M.R., Baglinière, J.L., 764 2004. An assessment of the upstream migration and reproductive behaviour of allis 765 shad (Alosa alosa L.) using acoustic tracking. ICES J. Mar. Sci. 61, 1291-1304. 
Acolas, M.L., Véron, V., Jourdan, H., Bégout, M.L., Sabatié, M.R., Baglinière, J.L., 2006. Upstream migration and reproductive patterns of a population of allis shad in a small river (L'Aulne, Brittany, France). ICES J. Mar. Sci. 63, 476-484.

Allee, W.C., 1931. Animal aggregations: a study in general sociology. University of Chigaco Press, Chicago 431 pp.

Aprahamian, M.W., Bagliniere, J.L., Sabatié, M.R., Alexandrino, P., Aprahamian, C.D., 2002. Synopsis of biological data on Alosa alosa and Alosa fallax spp., Warrington.

Araújo, M.B., Thuiller, W., Pearson, R.G., 2006. Climate warming and the decline of amphibians and reptiles in Europe. J. Biogeogr. 33, 1712-1728.

Baglinière, J.L., 2000. Le genre Alosa sp., in: Baglinière, J.L., Elie, P. (eds.), Les aloses (Alosa alosa et Alosa fallax spp.). Cemagref Editions - INRA Editions, Paris, pp. 330.

Bagliniere, J.L., Elie, P., 2000. Les aloses (Alosa alosa et Alosa fallax spp.) : écobiologie et variabilité des populations. Cemagref, Inra Éditions, Paris 275 pp.

Bagliniere, J.L., Maisse, G., 1985. Precocious maturation and smoltification in wild Atlantic salmon in the Armorican massif, France. Aquaculture 45, 249-263.

Baglinière, J.L., Sabatié, R., Rochard, E., Alexandrino, P., Aprahamian, M.W., 2003. The allis shad Alosa alosa: biology, ecology, range, and status of populations. Am. Fish. Soc. Symp. 35, 85-102.

Bal, G., Rivot, E., Prévost, E., Piou, C., Baglinière, J.L., 2011. Effect of water temperature and density of juvenile salmonids on growth of young-of-the-year Atlantic salmon Salmo salar. J. Fish Biol. 78, 1002-1022.

Barinaga, M., 1999. Salmon follow watery odors home. Science 286, 705-706. 
Barrows, C.W., Preston, K.L., Rotenberry, J.T., Allen, M.F., 2008. Using occurrence records to model historic distributions and estimate habitat losses for two psammophilic lizards. Biol. Conserv. 141, 1885-1893.

Berec, L., Angulo, E., Courchamp, F., 2007. Multiple Allee effects and population management. Trends Ecol. Evol. 22, 185-191.

Bevacqua, D., Andrello, M., Melià, P., Vincenzi, S., De Leo, G.A., Crivelli, A.J., 2011. Density-dependent and inter-specific interactions affecting European eel settlement in freshwater habitats. Hydrobiologia 671, 259-265.

Beverton, R.J.H., Holt, S.J., 1957. On the dynamics of exploited fish populations. Her majesty's stationery Office, London 553 pp.

Beyene, T., Lettenmaier, D.P., Kabat, P., 2010. Hydrologic impacts of climate change on the Nile River Basin: Implications of the 2007 IPCC scenarios. Clim. Change 100, $433-461$.

Bocedi, G., Pe'er, G., Heikkinen, R.K., Matsinos, Y., Travis, J.M.J., 2012. Projecting species' range expansion dynamics: sources of systematic biases when scaling up patterns and processes. Methods in Ecology and Evolution 3, 1008-1018.

Brooker, R.W., Travis, J.M.J., Clark, E.J., Dytham, C., 2007. Modelling species' range shifts in a changing climate: The impacts of biotic interactions, dispersal distance and the rate of climate change. J. Theor. Biol. 245, 59-65.

Brown, J.H., Gillooly, J.F., Allen, A.P., Savage, V.M., West, G.B., 2004. Toward a

810 Buisson, L., 2009. Poissons des rivières françaises et changement climatique : impacts sur la distribution des espèces et incertitudes des projections. Thèse de Doctorat. Institut National Polytechnique de Toulouse, Toulouse, p. 282. 
813 Buoro, M., Prévost, E., Gimenez, O., 2010. Investigating evolutionary trade-offs in wild

814 populations of Atlantic salmon (Salmo salar): Incorporating detection probabilities

815 and individual heterogeneity. Evolution 64, 2629-2642.

816 Cariboni, J., Gatelli, D., Liska, R., Saltelli, A., 2007. The role of sensitivity analysis in 817 ecological modelling. Ecol. Model. 203, 167-182.

818 Cassou-Leins, J.J., Cassou-Leins, F., Boisneau, P., Baglinière, J.L., 2000. La reproduction, 819 in: Baglinières, J.L., Elie, P. (eds.), Les aloses (Alosa alosa et Alosa fallax spp.). 820 Cemagref Editions - INRA Editions, Paris, pp. 73-92.

821 Caswell, H., John, A.M., 1992. From the individual to the population in demographic 822 models, in: DeAngelis, D.L., Gross, L.J. (eds.), Individual-based models and 823 approaches in ecology: populations, communities and ecosystems. Chapman et Hall, $824 \quad$ New York., pp. 36-61.

825 Charles, S., Subtil, F., Kielbassa, J., Pont, D., 2008. An individual-based model to describe 826 a bullhead population dynamics including temperature variations. Ecol. Model. 215,

828 Chesson, P., Lee, C.T., 2005. Families of discrete kernels for modeling dispersal. Theor. Popul. Biol. 67, 241-256.

830 Clobert, J., Danchin, E., Dhondt, A.A., Nichols, J.D., 2001. Dispersal. Oxford University Press, New York 452 pp.

832 Clobert, J., Le Galliard, J.-F., Cote, J., Meylan, S., Massot, M., 2009. Informed dispersal, 833 heterogeneity in animal dispersal syndromes and the dynamics of spatially structured 834 populations. Ecol. Lett. 12, 197-209.

835 De Leo, G.A., Gatto, M., 1995. A size and age-structured model of the European eel (Anguilla anguilla L.). Can. J. Fish. Aquat. Sci. 52, 1351-1367. 
837 Dekker, W., 2000. A Procrustean assessment of the European eel stock. ICES J. Mar. Sci.

$838 \quad 57,938-947$.

839 Dion, C.A., Hughes, N.F., 2004. Testing the ability of a temperature-based model to 840 predict the growth of age-0 arctic grayling. Trans. Am. Fish. Soc. 133, 1047-1050.

841 Droesbeke, J.J., Fine, J., Saporta, G., 1997. Plans d'expériences: applications à l'entreprise. 842 Editions Technip, Paris.

843 Drouineau, H., Mahévas, S., Bertignac, M., Fertin, A., 2008. Assessing the impact of 844 discretisation assumptions in a length-structured population growth model. Fisheries Research 91, 160-167.

846 Drouineau, H., Mahévas, S., Pelletier, D., Beliaeff, B., 2006. Assessing the impact of 847 different management options using ISIS-Fish: The French Merluccius merluccius 848 Nephrops norvegicus mixed fishery of the Bay of Biscay. Aquat. Living Resour. 19, $15-29$.

850 Dumoulin, N., 2007. SimAquaLife : un cadriciel pour la modélisation de la dynamique spatiale d'organismes aquatiques utilisant les métadonnées pour la production automatique de fonctionnalités. Techniques et Sciences Informatiques 26.

853 Engler, R., Guisan, A., 2009. MigClim: Predicting plant distribution and dispersal in a changing climate. Divers. Distrib. 15, 590-601.

Estes, L.D., Bradley, B.A., Beukes, H., Hole, D.G., Lau, M., Oppenheimer, M.G., Schulze, R., Tadross, M.A., Turner, W.R., 2013. Comparing mechanistic and empirical model projections of crop suitability and productivity: implications for ecological forecasting. Glob. Ecol. Biogeogr. 22, 1007-1018.

Evans, M.R., Grimm, V., Johst, K., Knuuttila, T., de Langhe, R., Lessells, C.M., Merz, M., O’Malley, M.A., Orzack, S.H., Weisberg, M., Wilkinson, D.J., Wolkenhauer, O., 

Evol. 28, 578-583.

Fabens, A.J., 1965. Properties and fitting of the Von Bertalanffy growth curve. Growth 29, 265-289.

865

866

867

868

869

870

Faivre, R., Iooss, B., Mahévas, S., Makowski, D., Monod, H., 2013. Analyse de sensibilité et exploration de modèles: application aux sciences de la nature et de l'environnement, Editions Quae ed, Versailles 352 pp.

Fennell, M., Murphy, J.E., Armstrong, C., Gallagher, T., Osborne, B., 2012. Plant Spread Simulator: A model for simulating large-scale directed dispersal processes across heterogeneous environments. Ecol. Model. 230, 1-10.

Fleming, I.A., 1996. Reproductive strategies of Atlantic salmon: Ecology and evolution. Rev. Fish Biol. Fish. 6, 379-416.

Forseth, T., Hurley, M.A., Jensen, A.J., Elliott, J.M., 2001. Functional models for growth and food consumption of Atlantic salmon parr, Salmo salar, from a Norwegian river. Freshw. Biol. 46, 173-186.

Frank, B.M., Baret, P.V., 2013. Simulating brown trout demogenetics in a river/nursery brook system: The individual-based model DemGenTrout. Ecol. Model. 248, 184202.

Franklin, J., 2010. Moving beyond static species distribution models in support of conservation biogeography. Divers. Distrib. 16, 321-330.

Friedland, K.D., 1998. Ocean climate influences on critical Atlantic salmon (Salmo salar) life history events. Can. J. Fish. Aquat. Sci. 55, 119-130.

Gallien, L., Münkemüller, T., Albert, C.H., Boulangeat, I., Thuiller, W., 2010. Predicting 884 potential distributions of invasive species: where to go from here? Divers. Distrib. $16,331-342$. 
886 Gardner, J.L., Peters, A., Kearney, M.R., Joseph, L., Heinsohn, R., 2011. Declining body

887 size: a third universal response to warming? Trends Ecol. Evol. 26, 285-291.

888 Gaston, K.J., Blackburn, T.M., 2002. Large-scale dynamics in colonization and extinction

889 for breeding birds in Britain. J. Anim. Ecol. 71, 390-399.

890 Gatto, M., Rossi, R., 1979. A method for estimating mortalities and abundances of the Valli Di Comacchio eels. Memorie dell'Istituto Italiano di Idrobiologia suppl. 37, 107-114.

Gienapp, P., Teplitsky, C., Alho, J.S., Mills, J.A., Meril̈̈, J., 2008. Climate change and 895 evolution: disentangling environmental and genetic responses. Mol. Ecol. 17, 167178.

897

Grimm, V., 1999. Ten years of individual-based modelling in ecology: what have we 8 learned and what could we learn in the future? Ecol. Model. 115, 129-148.

Grimm, V., Berger, U., Bastiansen, F., Eliassen, S., Ginot, V., Giske, J., Goss-Custard, J., Grand, T., Heinz, S.K., Huse, G., 2006. A standard protocol for describing individual-based and agent-based models. Ecol. Model. 198, 115-126.

901 Grimm, V., Berger, U., DeAngelis, D.L., Polhill, J.G., Giske, J., Railsback, S.F., 2010. The 902 ODD protocol: A review and first update. Ecol. Model. 221, 2760-2768.

903 Grimm, V., Railsback, S., 2005. Individual-based modeling and ecology. Princeton 904 University Press 413 pp.

905 Guisan, A., Thuiller, W., 2005. Predicting species distribution: offering more than simple 906 habitat models. Ecol. Lett. 8, 993-1009.

907 Guisan, A., Zimmermann, N.E., 2000. Predictive habitat distribution models in ecology. 908 Ecol. Model. 135, 147-186. 
909 Heikkinen, R.K., Luoto, M., Kuussaari, M., Toivonen, T., 2007. Modelling the spatial

910 distribution of a threatened butterfly: Impacts of scale and statistical technique.

$911 \quad$ Landsc. Urban Plann. 79, 347-357.

912 Hein, C.L., Öhlund, G., Englund, G., 2011. Dispersal through stream networks: modelling 913 climate-driven range expansions of fishes. Divers. Distrib., no-no.

914 Holling, C.S., 1966. The strategy of building models of complex ecological systems, in:

915 Watt, K.E.F. (ed.), Systems Analysis in Ecology. Academic Press, pp. 195-214.

916 Huntley, B., Barnard, P., Altwegg, R., Chambers, L., Coetzee, B.W.T., Gibson, L.,

917 Hockey, P.A.R., Hole, D.G., Midgley, G.F., Underhill, L.G., Willis, S.G., 2010.

918 Beyond bioclimatic envelopes: dynamic species' range and abundance modelling in 919 the context of climatic change. Ecography 33, 621-626.

920 Huntley, B., Collingham, Y.C., Green, R.E., Hilton, G.M., Rahbek, C., Willis, S.G., 2006. Potential impacts of climatic change upon geographical distributions of birds. Ibis

922 $148,8-28$.

Huston, M., DeAngelis, D., Post, W., 1988. New computers models unify ecological theory. Bioscience 38, 682-692.

925

Hutchings, J.A., Jones, M.E.B., 1998. Life history variation and growth rate thresholds for 926 maturity in Atlantic salmon, Salmo salar. Can. J. Fish. Aquat. Sci. 55, 22-47.

Jackson, S.T., Betancourt, J.L., Booth, R.K., Gray, S.T., 2009. Ecology and the ratchet of events: Climate variability, niche dimensions, and species distributions. Proceedings of the National Academy of Sciences 106, 19685-19692.

930 Jager, H.I., Cardwell, H.E., Sale, M.J., Bevelhimer, M.S., Coutant, C.C., Van Winkle, W., 1997. Modelling the linkages between flow management and salmon recruitment in rivers. Ecol. Model. 103, 171-191. 
933 Jager, H.I., Peterson, D.L., Farrae, D., Bevelhimer, M.S., 2013. A population model to 934 assess influences on the viability of the Shortnose sturgeon population in the Ogeechee river, Georgia. Trans. Am. Fish. Soc. 142, 731-746.

Jonsson, B., Jonsson, N., 2009. A review of the likely effects of climate change on anadromous Atlantic salmon Salmo salar and brown trout Salmo trutta, with particular reference to water temperature and flow. J. Fish Biol. 75, 2381-2447.

Keith, D.A., Akçakaya, H.R., Thuiller, W., Midgley, G.F., Pearson, R.G., Phillips, S.J., Regan, H.M., Araújo, M.B., Rebelo, T.G., 2008. Predicting extinction risks under climate change: coupling stochastic population models with dynamic bioclimatic habitat models. Biology Letters 4, 560-563.

Kerr, J.T., Dobrowski, S.Z., 2013. Predicting the impacts of global change on species, communities and ecosystems: it takes time. Glob. Ecol. Biogeogr. 22, 261-263.

Kielbassa, J., Delignette-Muller, M.L., Pont, D., Charles, S., 2010. Application of a temperature-dependent von Bertalanffy growth model to bullhead (Cottus gobio). Ecol. Model. 221, 2475-2481.

948 Kinnison, M.T., Hairston, N.G., 2007. Eco-evolutionary conservation biology: contemporary evolution and the dynamics of persistence. Funct. Ecol. 21, 444-454.

Kleijnen, J.P.C., 1998. Experimental design for sensitivity analysis, optimization, and validation of simulation models, in: Banks, J. (ed.), Handbook of simulation. Principles, Methodology, Advances, Applications and Practise. John Wiley, New York, pp. 173-224.

Kottelat, M., Freyhof, J., 2007. Handbook of European freshwater fishes. Kottelat, Cornol, Switzerland and Freyhof, Berlin, Germany 646 pp. 
956 Lambert, P., 2005. Exploration multiscalaire des paradigmes de la dynamique de la 957 population d'anguilles européennes à l'aide d'outils de simulation. Thèse de Doctorat. 958 Université Bordeaux I, Bordeaux, p. 224.

959 Lambert, P., Martin-Vandembulcke, D., Rochard, E., Bellariva, J.L., Castelnaud, G., 2001. 960 Age à la migration de reproduction des géniteurs de trois cohortes de grandes aloses 961 (Alosa alosa) dans le bassin versant de la Garonne (France) la (France). Bull. Fr. $962 \quad$ Peche Piscic. 362/363, 973-987.

963 Lambert, P., Rochard, E., 2007. Identification of the inland population dynamics of the 964 European eel using a pattern-oriented modelling. Ecol. Model. 206, 166-178.

965 LANUV, 2010. The reintroduction of the allis shad (Alosa alosa) to the Rhine System 966 Life project - LANUV-Fachbericht 28. Recklinghausen.

967 Lassalle, G., 2008. Impacts des changements globaux sur la distribution des poissons 968 migrateurs amphihalins, une approche par modélisation à l'échelle continentale. Thèse de Doctorat. Université Bordeaux I, Bordeaux, p. 244.

970 Lassalle, G., Béguer, M., Beaulaton, L., Rochard, E., 2008a. Diadromous fish conservation plans need to consider global warming issues: An approach using biogeographical models. Biol. Conserv. 141, 1105-1118.

974 predict the future: responses of European diadromous fish to climate change, in: Haro, A.J., Smith, K.L., Rulifson, R.A., Moffitt, C.M., Klauda, R.J., Dadswell, M.J., Cunjak, R.A., Cooper, J.E., Beal, K.L., Avery, T.S. (eds.), Challenges for diadromous fishes in a dynamic global environment, vol. Symposium 69. American Fisheries Society, Bethesda, Maryland, pp. 175-193. 
979 Lassalle, G., Trancart, T., Lambert, P., Rochard, E., 2008b. Latitudinal variations in age $980 \quad$ and size at maturity among allis shad Alosa alosa populations. J. Fish Biol. 73, 17991809.

982 Lehuta, S., Mahévas, S., Petitgas, P., Pelletier, D., 2010. Combining sensitivity and uncertainty analysis to evaluate the impact of management measures with ISIS-Fish: marine protected areas for the Bay of Biscay anchovy (Engraulis encrasicolus) fishery. ICES Journal of Marine Science: Journal du Conseil 67, 1063-1075.

Levins, R., 1966. The strategy of model building in population ecology. Am. Sci. 54, 421431.

Limburg, K.E., Waldman, J.R., 2009. Dramatic declines in north Atlantic diadromous fishes. Bioscience 59, 955-965.

990 Lochet, A., Jatteau, P., Tomàs, J., Rochard, E., 2008. Retrospective approach to investigating the early life history of a diadromous fish: Allis shad Alosa alosa (L.) in the Gironde-Garonne-Dordogne watershed. J. Fish Biol. 72, 946-960.

993

Loss, S.R., Terwilliger, L.A., Peterson, A.C., 2011. Assisted colonization: Integrating conservation strategies in the face of climate change. Biol. Conserv. 144, 92-100.

MacKenzie, B.R., Gislason, H., Möllmann, C., Köster, F.W., 2007. Impact of 21st century 996 climate change on the Baltic Sea fish community and fisheries. Global Change Biology 13, 1348-1367.

Mallet, J.P., Charles, S., Persat, H., Auger, P., 1999. Growth modelling in accordance with daily water temperature in European grayling (Thymallus thymallus L.). Can. J. Fish. Aquat. Sci. 56, 994-1000.

Mangel, M., 1994. Climate change and salmonid life history variation. Deep-Sea Research Part II: Topical Studies in Oceanography 41, 75-106. 
1003 Martin Vandembulcke, D., 1999. Dynamique de population de la grande alose (Alosa 1004 alosa, L. 1758) dans le bassin versant Gironde-Garonne-Dordogne (France): analyse 1005 et prévision par modélisation. Thèse de Doctorat. Ecole Nationale Polytechnique, 1006 Toulouse, p. 155.

1007 McCauley, S.J., Mabry, K.E., 2011. Climate change, body size, and phenotype dependent 1008 dispersal. Trends Ecol. Evol. 26, 554-555.

1009 McDowall, R.M., 1988. Diadromy in fishes: migration between freshwater and marine 1010 environments. Croom Helm, London 308 pp.

1011 McDowall, R.M., 1997. The evolution of diadromy in fishes (revisited) and its place in phylogenetic analysis. Rev. Fish Biol. Fish. 7, 443-462.

1013 McDowall, R.M., 2009. Making the best of two worlds: diadromy in the evolution, 1014 ecology, and conservation of aquatic organisms, in: Haro, A.J., Smith, K.L., 1015 Rulifson, R.A., Moffitt, C.M., Klauda, R.J., Dadswell, M.J., Cunjak, R.A., Cooper, 1016 J.E., Beal, K.L., Avery, T.S. (eds.), Challenges for diadromous fishes in a dynamic 1017 global environment. American Fisheries Society, Symposium 69, Berthesda, $1018 \quad$ Maryland, pp. 1-22.

1019 Mennesson-Boisneau, C., Aprahamian, M.W., Sabatié, M.R., Cassou-Leins, J.J., 2000a. 1020 Caractéristiques des adultes, in: Baglinière, J.L., Elie, P. (eds.), Les aloses (Alosa alosa et Alosa fallax spp.). Cemagref Editions - INRA Editions, Paris, pp. 33-54.

1022 Mennesson-Boisneau, C., Aprahamian, M.W., Sabatié, M.R., Cassou-Leins, J.J., $2000 b$. 1023 Remontée migratoire des adultes, in: Baglinière, J.L., Elie, P. (eds.), Les aloses 1024 (Alosa alosa et Alosa fallax spp.). Cemagref Editions - INRA Editions, Paris, pp. 5572. 
1026 Mennesson-Boisneau, C., Boisneau, P., 1990. Migration, répartition, reproduction, caractéristiques biologiques et taxonomie des aloses (Alosa sp) dans le bassin de la Loire. Université Rennes I et Paris XII, p. 143.

Merow, C., Lafleur, N., Silander Jr, J.A., Wilson, A.M., Rubega, M., 2011. Developing dynamic mechanistic species distribution models: Predicting bird-mediated spread of invasive plants across northeastern North America. Am. Nat. 178, 30-43.

Midgley, G.F., Davies, I.D., Albert, C.H., Altwegg, R., Hannah, L., Hughes, G.O., Ecography 33, 612-616.

Midgley, G.F., Hannah, L., Millar, D., Rutherford, M.C., Powrie, L.W., 2002. Assessing the vulnerability of species richness to anthropogenic climate change in a biodiversity hotspot. Glob. Ecol. Biogeogr. 11, 445-451.

Milly, P.C.D., Dunne, K.A., Vecchia, A.V., 2005. Global pattern of trends in streamflow and water availability in a changing climate. Nature 438, 347-350.

Mota, M., Antunes, C., 2011. First report on the status of Allis shad (Alosa alosa) in the Minho River (Northwestern Iberian Peninsula). J. Appl. Ichthyol. 27, 56-59.

Nicolas, D., Chaalali, A., Drouineau, H., Lobry, J., Uriarte, A., Borja, A., Boët, P., 2011. Impact of global warming on European tidal estuaries: some evidence of northward

1046 O'Sullivan, D., Perry, G.L.W., 2009. A discrete space model for continuous space dispersal processes. Ecological Informatics 4, 57-68.

Parmesan, C., Yohe, G., 2003. A globally coherent fingerprint of climate change impacts across natural systems. Nature 421, 37-42. 
1050 Peterson, R.H., Spinney, H.C.E., Sreedharan, A., 1977. Development of atlantic salmon (Salmo salar) eggs and alevins under varied temperature regimes. J. Fish. Res. Board Can. 34, 31-43.

Piou, C., Prévost, E., 2012. A demo-genetic individual-based model for Atlantic salmon populations: Model structure, parameterization and sensitivity. Ecol. Model. 231, 3752.

Piou, C., Prévost, E., 2013. Contrasting effects of climate change in continental vs. oceanic environments on population persistence and microevolution of Atlantic salmon. Global Change Biology 19, 711-723.

Prouzet, P., Martinet, J.P., Badia, J., 1994. Biological characteristics and catch variation of allis shad (Alosa alosa) from commercial catches in the Adour River (Pyrenees atlantiques, France). Aquat. Living Resour. 7, 1-10.

1063

Pulliam, H.R., 2000. On the relationship between niche and distribution. Ecol. Lett. 3, 349-

Qi, S., Sun, G., Wang, Y., McNulty, S.G., Myers, J.A.M., 2009. Streamflow response to climate and landuse changes in a coastal watershed in North Carolina. Transactions of the ASABE 52, 739-749.

1068

Quinn, T.P., Doctor, K., Kendall, N., Rich, H.B., 2009. Diadromy and the life history of sockeye salmon: nature, nurture and the hand of man, in: Haro, A.J., Smith, K.L., Rulifson, R.A., Moffitt, C.M., Klauda, R.J., Dadswell, M.J., Cunjak, R.A., Cooper,

1073 R Core Team, 2013. R: A language and environment for statistical computing. 
1074 Reed, T.E., Schindler, D.E., Hague, M.J., Patterson, D.A., Meir, E., Waples, R.S., Hinch,

1075

1076

1077

1078

1079

1080

1081

1082

1083

1084

1085

1086

1087

1088

1089

1090

1091

1092

1093

1094

1095

1096

1097

S.G., 2011. Time to evolve? Potential evolutionary responses of Fraser river sockeye salmon to climate change and effects on persistence. PLoS ONE 6, e20380.

Reuillon, R., Leclaire, M., Rey-Coyrehourcq, S., 2013. OpenMOLE, a workflow engine specifically tailored for the distributed exploration of simulation models. Future Generation Computer Systems 29, 1981-1990.

Rivot, E., Prevost, E., Parent, E., Bagliniere, J.L., 2004. A Bayesian state-space modelling framework for fitting a salmon stage-structured population dynamic model to multiple time series of field data. Ecol. Model. 179, 463-485.

Rochard, E., Lambert, P., 2011. Chapter 30 Modelling the future of stocked fish. Biology and conservation of the Atlantic European sturgeon Acipenser sturio L., 1758, 417424.

Ronce, O., 2007. How does it feel to be like a rolling stone? Ten questions about dispersal evolution. Annual Review of Ecology, Evolution, and Systematics 38, 231-253.

Rosso, L., Lobry, J.R., Bajard, S., Flandrois, J.P., 1995. Convenient model to describe the combined effects of temperature and $\mathrm{pH}$ on microbial growth. Appl. Environ. Microbiol. 61, 610-616.

Rougier, T., Lambert, P., Drouineau, H., Girardin, M., Castelnaud, G., Carry, L., Aprahamian, M., Rivot, E., Rochard, E., 2012. Collapse of allis shad, Alosa alosa, in the Gironde system (southwest France): environmental change, fishing mortality, or Allee effect? ICES Journal of Marine Science: Journal du Conseil 69, 1802-1811.

Saltelli, A., 2004. What is sensitivity analysis?, in: Saltelli, A., Chan, K., Scott, E.M. (eds.), Sensitivity Analysis. Probability and Statistics Series. John Wiley, New york. 475 pp, pp. 3-13. 
Saltelli, A., Ratto, M., Andres, T., Campolongo, F., Cariboni, J., Gatelli, D., Saisana, Tarantola, S., 2008. Global sensitivity analysis: the primer. Wiley, New York.

1100 Seddon, P.J., Armstrong, D.P., Soorae, P., Launay, F., Walker, S., Ruiz-Miranda, C.R.,

1101 Molur, S., Koldewey, H., Kleiman, D.G., 2009. The risks of assisted colonization. $1102 \quad$ Conserv. Biol. 23, 788-789.

1103 Segurado, P., Araújo, M.B., 2004. An evaluation of methods for modelling species 1104 distributions. J. Biogeogr. 31, 1555-1568.

1105 Slone, D.H., 2011. Increasing accuracy of dispersal kernels in grid-based population models. Ecol. Model. 222, 573-579.

1107 Stephens, P.A., Sutherland, W.J., Freckleton, R.P., 1999. What is the Allee effect? Oikos 87, 185-190.

1109 Thomas, C.D., Cameron, A., Green, R.E., Bakkenes, M., Beaumont, L.J., Collingham, 1110 Y.C., Erasmus, B.F.N., Ferreira De Siqueira, M., Grainger, A., Hannah, L., Hughes,

1111 L., Huntley, B., Van Jaarsveld, A.S., Midgley, G.F., Miles, L., Ortega-Huerta, M.A., 1112 Peterson, A.T., Phillips, O.L., Williams, S.E., 2004. Extinction risk from climate $1113 \quad$ change. Nature 427, 145-148.

1114 Thomas, C.D., Lennon, J.J., 1999. Birds extend their ranges northwards. Nature 399, 213.

1115 Thuiller, W., 2003. BIOMOD - optimizing predictions of species distributions and 1116 projecting potential future shifts under global change. Global Change Biology 9, $1117 \quad 1353-1362$.

1118 Thuiller, W., Albert, C., Araújo, M.B., Berry, P.M., Cabeza, M., Guisan, A., Hickler, T., 1119 Midgley, G.F., Paterson, J., Schurr, F.M., Sykes, M.T., Zimmermann, N.E., 2008. 1120 Predicting global change impacts on plant species' distributions: Future challenges. 1121 Perspectives in Plant Ecology, Evolution and Systematics 9, 137-152. 
1122 Thuiller, W., Broennimann, O., Hughes, G., Alkemade, J.R.M., Midgley, G.F., Corsi, F.,

1123 2006. Vulnerability of African mammals to anthropogenic climate change under 1124 conservative land transformation assumptions. Global Change Biology 12, 424-440.

1125 Tomas, J., Augagneur, S., Rochard, E., 2005. Discrimination of the natal origin of young1126 of-the-year Allis shad (Alosa alosa) in the Garonne-Dordogne basin (south-west 1127 France) using otolith chemistry. Ecol. Freshw. Fish. 14, 185-190.

1128 Travis, J.M.J., Mustin, K., Bartoń, K.A., Benton, T.G., Clobert, J., Delgado, M.M., 1129 Dytham, C., Hovestadt, T., Palmer, S.C.F., Van Dyck, H., Bonte, D., 2012. 1130 Modelling dispersal: an eco-evolutionary framework incorporating emigration, 1131 movement, settlement behaviour and the multiple costs involved. Methods in 1132 Ecology and Evolution 3, 628-641.

1133 Van Winkle, W., Jager, H.I., Railsback, S.F., Holcomb, B.D., Studley, T.K., Baldrige, J.E., 1134 1998. Individual-based model of sympatric populations of brown and rainbow trout for instream flow assessment: model description and calibration. Ecol. Model. 110, 175-207.

1137 Van Winkle, W., Rose, K.A., Chambers, R.C., 1993. Individual-based approach to fish 1138 population dynamics: An overview. Trans. Am. Fish. Soc. 122, 397-403.

1139 Visser, M.E., 2008. Keeping up with a warming world; assessing the rate of adaptation to 1140 climate change. Proceedings of the Royal Society B: Biological Sciences 275, 649659.

1142 Vollestad, L.A., Jonsson, B., 1988. A 13-year study of the population dynamics and 1143 growth of the European eel Anguilla anguilla in a Norwegian river: Evidence for 1144 density-dependent mortality, and development of a model for predicting yield. J. $1145 \quad$ Anim. Ecol. 57, 983-997. 
1146 von Bertalanffy, L., 1938. A quantitative theory of organic growth. Hum. Biol. 10, 1811147213.

1148 Vrieze, L.A., Sorensen, P.W., 2001. Laboratory assessment of the role of a larval 1149 pheromone and natural stream odor in spawning stream localization by migratory sea 1150 lamprey (Petromyzon marinus). Can. J. Fish. Aquat. Sci. 58, 2374-2385.

1151 Walther, G.R., Post, E., Convey, P., Menzel, A., Parmesan, C., Beebee, T.J.C., Fromentin, 1152 J.M., Hoegh-Guldberg, O., Bairlein, F., 2002. Ecological responses to recent climate $1153 \quad$ change. Nature 416, 389-395.

1154 Wheeler, B., 2011. AlgDesign: Algorithmic Experimental Design. R package version 1.11155 7. http://CRAN.R-project.org/package=AlgDesign.

1156 Zimmermann, N.E., Yoccoz, N.G., Edwards Jr, T.C., Meier, E.S., Thuiller, W., Guisan, A., 1157 Schmatz, D.R., Pearman, P.B., 2009. Climatic extremes improve predictions of 1158 spatial patterns of tree species. Proc. Natl. Acad. Sci. U. S. A. 106, 19723-19728. 


\section{List of tables :}

Table1. List of agents intervening in the GR3D individual-based model, with their state variables and corresponding status or measure unit.

\begin{tabular}{llll}
\hline Agent & State Variable & Descritpion & Status/unit of measure \\
\hline Sea basin & name & Name ID & SB and a number \\
\multirow{3}{*}{ River basin } & seasonal temperature & Water temperature & Numeric $\left({ }^{\circ} \mathrm{C}\right)$ \\
& name & Name ID & RB and a number \\
& longitude & Longitude at the mouth & Numeric $\left({ }^{\circ}\right)$ \\
& latitude & Latitude at the mouth & Numeric $\left({ }^{\circ}\right)$ \\
& watershed area & Watershed area of the & Numeric $\left(\mathrm{km}^{2}\right)$ \\
Diadromous fish & river basin & Numeric $\left({ }^{\circ} \mathrm{C}\right)$ \\
& seasonal temperature & Water temperature & Numeric $(-)$ \\
& ID & Fish identification & M, F \\
& gender & Sex & Mature, immature \\
& stage & Stage & Numeric $(-)$ \\
& age & Age & Numeric $(\mathrm{cm})$ \\
& body-length & Body length & Name of the compartment \\
& location & Current location & Name of the birth \\
& birth place & Birth place & compartment \\
& number of reproduction & Number of reproduction & Numeric $(-)$ \\
\hline
\end{tabular}


Table 2. GR3D parameters description and selected nominal values for the test case with allis

shad.

\begin{tabular}{|c|c|c|c|}
\hline Parameter name & Description & Value & Reference or remarks \\
\hline \multicolumn{4}{|l|}{ Reproduction } \\
\hline repSeason & Season of the reproduction & Spring & $\begin{array}{l}\text { (Mennesson-Boisneau et al., } \\
\text { 2000b) }\end{array}$ \\
\hline$\Delta t_{r e c}$ & $\begin{array}{l}\text { Assumed age of juvenile } \\
\text { produced by the reproduction } \\
\text { (Year) }\end{array}$ & 0.33 & $\begin{array}{l}\text { As we assumed that recruitment } \\
\text { were juveniles in estuary, we used } \\
\text { the study from Lochet et al. } \\
\text { (2008) }\end{array}$ \\
\hline$\eta$ & $\begin{array}{l}\text { Parameter to relate } S_{95, j} \text { and } \\
\text { the surface of a spawning } \\
\text { place }\left(\mathrm{Ind} / \mathrm{km}^{2}\right)\end{array}$ & 2.4 & $\begin{array}{l}\text { Offline calibration using the study } \\
\text { from Rougier et al. (2012) }\end{array}$ \\
\hline$\theta$ & $\begin{array}{l}\text { Ratio between } S_{95, j} \text { and } \\
S_{50, j} \text { in each spawning place }\end{array}$ & 1.9 & $\begin{array}{l}\text { Offline calibration using the study } \\
\text { from Rougier et al. (2012) }\end{array}$ \\
\hline $\mathrm{a}$ & $\begin{array}{l}\text { Parameter of the S-R } \\
\text { relationship linked to the } \\
\text { fecundity of the studied } \\
\text { species (Eggs/individual) }\end{array}$ & 135000 & $\begin{array}{l}\text { (Cassou-Leins et al., 2000; } \\
\text { LANUV, 2010) }\end{array}$ \\
\hline surv optRep $_{1}$ & $\begin{array}{l}\text { Optimal survival rate of an } \\
\text { individual from eggs to the } \\
\text { age } \Delta t_{\text {rec }}\end{array}$ & $1.7 * 10^{-3}$ & $\begin{array}{l}\text { Offline calibration using the study } \\
\text { from Rougier et al. (2012) }\end{array}$ \\
\hline$T_{\operatorname{minRep}}, T_{\text {optRep }}, T_{\operatorname{maxRep}}$ & $\begin{array}{l}\text { Water temperature }\left({ }^{\circ} \mathrm{C}\right) \\
\text { regulating survival of an } \\
\text { individual from eggs to the } \\
\text { age } \Delta t_{\text {rec }}\end{array}$ & $14,20,26$ & $\begin{array}{l}\text { (Cassou-Leins et al., 2000; } \\
\text { Kottelat and Freyhof, 2007) }\end{array}$ \\
\hline$\lambda$ & $\begin{array}{l}\text { Parameter to relate } c_{j} \text { and the } \\
\text { surface of a spawning place }\end{array}$ & $4.1 * 10^{-4}$ & $\begin{array}{l}\text { Offline calibration using the study } \\
\text { from Rougier et al. (2012) }\end{array}$ \\
\hline$\sigma_{\text {rep }}$ & $\begin{array}{l}\text { Standard deviation of log- } \\
\text { normal distribution of the } \\
\text { recruitment }\end{array}$ & 0.2 & Reasonable guessed \\
\hline$S p_{s p}$ & $\begin{array}{l}\text { Survival probability of } \\
\text { spawners after reproduction } \\
\text { (i.e. iteroparous rate) }\end{array}$ & 0.1 & $\begin{array}{l}\text { (Mennesson-Boisneau et al., } \\
\text { 2000b) }\end{array}$ \\
\hline \multicolumn{4}{|l|}{ Downstream migration } \\
\hline downMigAge & $\begin{array}{l}\text { Age of individual when it runs } \\
\text { toward the sea (Year) }\end{array}$ & 0.33 & $\begin{array}{l}\text { (Lochet et al., 2008); } \\
\text { In the test case, this migration } \\
\text { concerns also spawners which } \\
\text { survive after reproduction but, as } \\
\text { mature individuals, they migrate } \\
\text { automatically at sea the season } \\
\text { following the reproduction }\end{array}$ \\
\hline downMigSeason & $\begin{array}{l}\text { Season of the run of } \\
\text { individuals toward the sea }\end{array}$ & summer & $\begin{array}{l}\text { In the test case, both juveniles and } \\
\text { spawners which survive after } \\
\text { reproduction migrate in summer } \\
\text { (Cassou-Leins et al., 2000) }\end{array}$ \\
\hline \multicolumn{4}{|l|}{ Growth } \\
\hline$L_{i n i}$ & $\begin{array}{l}\text { Initial length of juvenile in } \\
\text { estuary }(\mathrm{cm})\end{array}$ & 2 & $\begin{array}{l}\text { As we considered juveniles in } \\
\text { estuary, we used the study from } \\
\text { Lochet et al. (2008) }\end{array}$ \\
\hline$\sigma_{\Delta L}$ & $\begin{array}{l}\text { Standard deviation of log- } \\
\text { normal distribution of the }\end{array}$ & 0.2 & Reasonable guessed \\
\hline
\end{tabular}




$$
\begin{aligned}
& L_{\infty} \\
& T_{\text {minGrow }}, T_{\text {optGrow }}, \\
& T_{\text {maxGrow }}, \\
& \kappa_{\text {optGrow }}
\end{aligned}
$$

\section{Survival}

$Z_{\text {sea }}$
$H_{r i v}$
$T_{\text {minSurvRiv }}, T_{\text {optSurvRiv }}$,
$T_{\text {maxSurvRiv }}$

Surv ${ }_{\text {optRiv }}$

\section{Maturation}

$L_{\text {mat }}$

\section{Upstream migration}

upMigAge

upMigSeason

$p_{\text {hom }}$

$\alpha_{\text {const }}, \alpha_{\text {dist }}, \alpha_{T L}$,

$\alpha_{W A}$

$\overline{D_{j-\text { birthPlace }}}$,

$\sigma_{j-\text { birthPlace }}, \overline{T L}, \sigma_{T L}$,

$\overline{W A}, \sigma_{W A}$

$w^{\text {deathBasin }}$ growth increment

Asymptotic length of the individual $(\mathrm{cm})$

60

Water temperature $\left({ }^{\circ} \mathrm{C}\right)$

regulating the growth

$3,17,26$

(cm/season)

Annual mortality coefficient at sea $\left(\right.$ Year $\left.^{-1}\right)$

Annual mortality (different

from natural) coefficient in river $\left(\right.$ Year $\left.^{-1}\right)$

Water temperature $\left({ }^{\circ} \mathrm{C}\right)$

regulating survival of

$10,20,23$ individual in river

Optimal natural survival rate of individuals in river $\left(\mathrm{Year}^{-1}\right)$

Length at first maturity $(\mathrm{cm})$

Age of individual when it runs toward the river (Year)

Season of the return of spawners in river for spawning Probability to do natal homing behavior

spring

Parameters of the logit function used to determine the weight of each accessible basin for dispersers

Mean and standard deviation used for standard core values in the logit function

$300,978,-,-,-,-$

Weigth of the death basin used to introduced a mortality of dispersers
(Mennesson-Boisneau et al., 2000a)

Reasonable guessed

(Bagliniere and Elie, 2000;

Aprahamian et al., 2002)

Reasonable guessed based upon Rougier et al. (2012)

Reasonable guessed to 0 to limit the complexity of the test case

In the test case, it concerns only spawners during the reproduction run and this phase has been shown highly dependent of water temperature (Cassou-Leins et al., 2000; Kottelat and Freyhof, 2007) Natural mortality was assumed to be negligible at optimal conditions during the reproduction run as it concerns a short period of 3 months (CassouLeins et al., 2000)

(Cassou-Leins et al., 2000; Lassalle et al., 2008b)

In the test case, this migration concerns only mature individuals and is not age-specific consequently

All mature individuals at sea migrate in river at this season

(Tomas et al., 2005)

Reasonable guessed assuming a weight of 0.95 and 0.05 for a basin located at a distance of $-2.9,19.7,0,0 \quad 10 \mathrm{~km}$ and $300 \mathrm{~km}$ respectively and assuming no effect of individual size and surface of basins on dispersal

Reasonable guessed assuming that $300 \mathrm{~km}$ was close to the maximal distance of allis shad dispersal and from EuroDiad 2.0 database (Lassalle, 2008). Parameters linked to fish length and surface basin were not relevant in the test case.
Reasonable guessed 
Table 3. Uncertain population dynamics parameters of the GR3D model and environmental parameters tested in the sensitivity analysis of the test case.

\begin{tabular}{|c|c|c|}
\hline Parameter name & Tested values & $\begin{array}{l}\text { Selected for complete } \\
\text { sampling (Yes or No) }\end{array}$ \\
\hline \multicolumn{3}{|c|}{ Reproduction SM1 } \\
\hline$\eta$ & {$[2.2 ; 2.6]$} & $\mathrm{N}$ \\
\hline$\theta$ & {$[1.8 ; 2]$} & $\mathrm{Y}$ \\
\hline surv $v_{\text {optRep }}$ & {$\left[1 * 10^{-3} ; 2 * 10^{-3}\right]$} & $\mathrm{Y}$ \\
\hline$T_{m i n R e p}$ & {$[13.3 ; 14.6]$} & $\mathrm{N}$ \\
\hline$T_{\text {optRep }}$ & {$[19.3 ; 20.6]$} & $\mathrm{Y}$ \\
\hline$T_{\text {maxRep }}$ & {$[25.3 ; 26.6]$} & $\mathrm{N}$ \\
\hline$\lambda$ & {$\left[3 * 10^{-4} ; 5 * 10^{-4}\right]$} & $\mathrm{Y}$ \\
\hline$\sigma_{r e p}$ & {$[0.1 ; 0.3]$} & $\mathrm{N}$ \\
\hline \multicolumn{3}{|l|}{ Growth SM2 } \\
\hline$\sigma_{\Delta L}$ & {$[0.1 ; 0.3]$} & $\mathrm{N}$ \\
\hline$T_{\min \text { Grow }}$ & {$[2.3 ; 3.6]$} & $\mathrm{N}$ \\
\hline$T_{\text {optGrow }}$ & {$[16.3 ; 17.6]$} & $\mathrm{Y}$ \\
\hline$T_{\text {maxGrow }}$ & {$[25.3 ; 26.6]$} & $\mathrm{N}$ \\
\hline$\kappa_{\text {optGrow }}$ & {$[0.2 ; 0.4]$} & $\mathrm{Y}$ \\
\hline \multicolumn{3}{|l|}{ Survival SM3 } \\
\hline$Z_{\text {sea }}$ & {$[0.3 ; 0.5]$} & $\mathrm{Y}$ \\
\hline$T_{\text {minSurvRiv }}$ & {$[9.3 ; 10.6]$} & $\mathrm{N}$ \\
\hline$T_{\text {optSurvRiv }}$ & {$[19.3 ; 20.6]$} & $\mathrm{Y}$ \\
\hline$T_{\text {maxSurvRiv }}$ & {$[22.3 ; 23.6]$} & $\mathrm{N}$ \\
\hline \multicolumn{3}{|l|}{ Maturation SM5 } \\
\hline$L_{m a t}$ & {$[36 ; 44]$} & $\mathrm{Y}$ \\
\hline \multicolumn{3}{|c|}{ Anadromous migration SM6 } \\
\hline$p_{\text {hom }}$ & {$[0.6 ; 0.9]$} & $\mathrm{Y}$ \\
\hline$w^{\text {deathBasin }}$ & {$[0.2 ; 0.6]$} & $\mathrm{N}$ \\
\hline \multicolumn{3}{|c|}{ Environmental parameters } \\
\hline WA_RB2 & [20000; 40000; 80000] & $\mathrm{Y}$ \\
\hline intDist & {$[100 ; 300 ; 600 ; 900]$} & $\mathrm{Y}$ \\
\hline
\end{tabular}


Table 4. Percentage of explained deviance (for $f_{s} P$ and $f_{s} S$ ) and explained variance (for $m l r$ )

by the model applied to outputs variables according to the experimental.

\begin{tabular}{llll}
\hline & \multicolumn{3}{c}{ Output variable } \\
\cline { 2 - 4 } Design & $f_{s} P$ & $f_{s} S$ & $\mathrm{mlr}$ \\
\hline D-Optimal design & $78 \%$ & $70 \%$ & $60 \%$ \\
Complete sampling & & & \\
$\quad$ Without interaction effects & $81 \%$ & $69 \%$ & $54 \%$ \\
$\quad$ With interaction effects & $90 \%$ & $85 \%$ & $79 \%$ \\
\hline
\end{tabular}




\section{List of figures :}

Fig. 1. Conceptual diagram of the life cycle of anadromous species (adapted for allis shad) represented in the GR3D individual-based model.

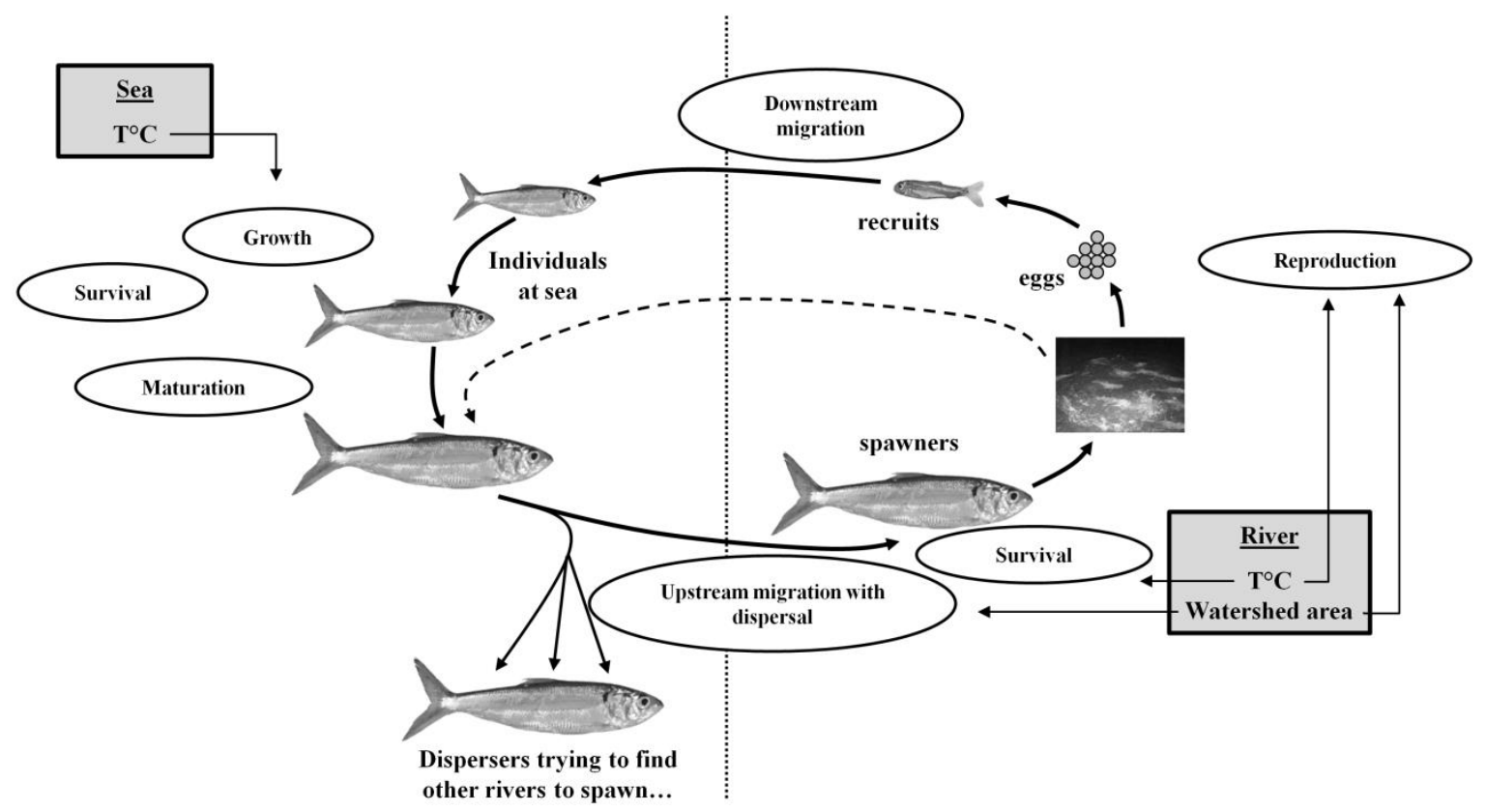


Fig. 2. Illustrative example of simulation results over 200 years showing the dynamics over time of the recruitment in RB1 and RB2 using the nominal values of the model parameters and with (A) a distance of $300 \mathrm{~km}$ between RB1 and RB2 and a success of the colonization of RB2 $(f s=2)$, (B) a distance of $600 \mathrm{~km}$ between RB1 and RB2 and very low recruitments in $\mathrm{RB} 2$ at the end of simulation $(f s=1)$, and $(\mathrm{C})$ a distance of $900 \mathrm{~km}$ between RB1 and RB2 and no colonization of RB2 $\left(f_{s}=0\right)$.
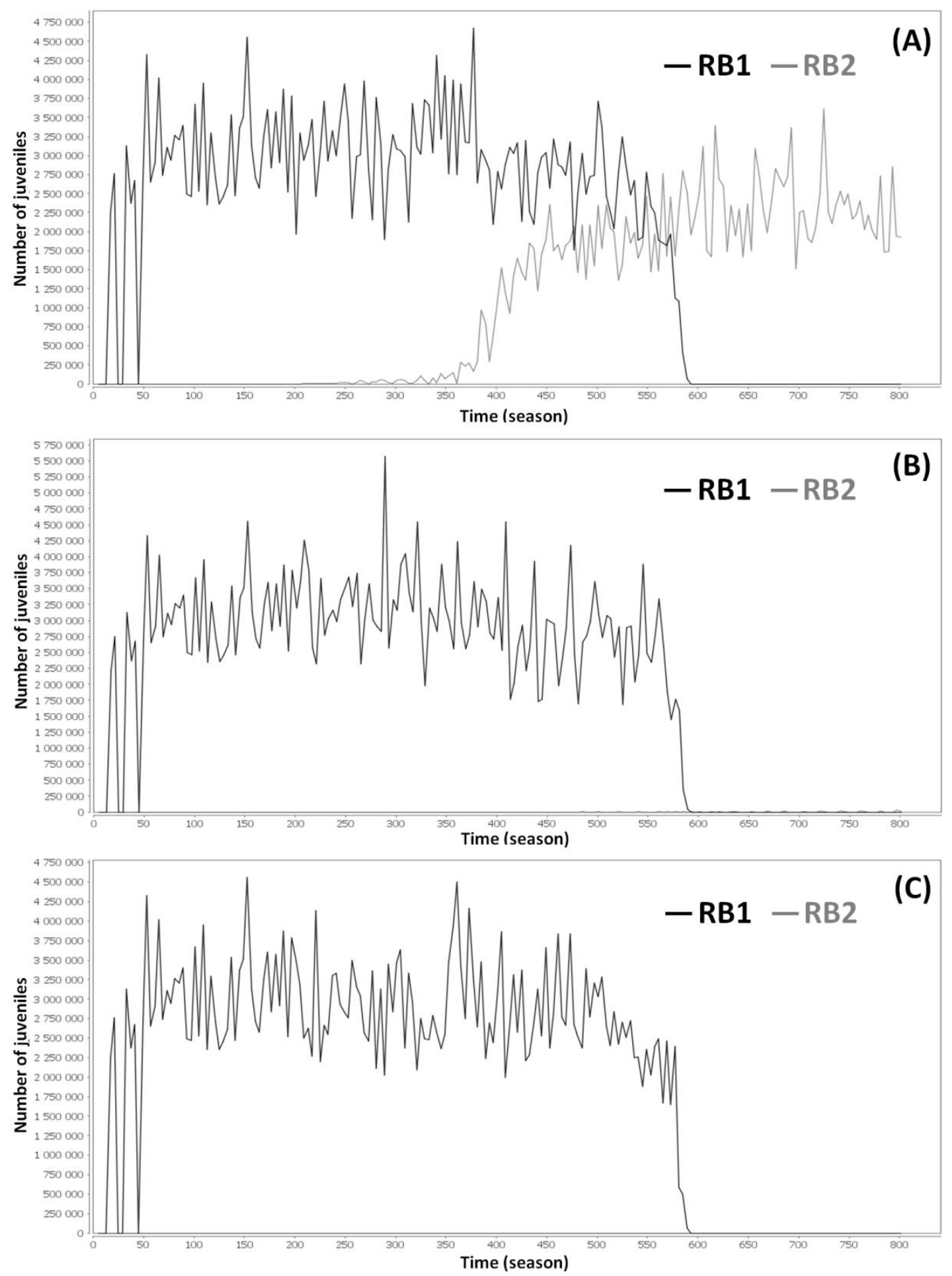
Fig. 3. Ten highest SI values (in \%; the higher the percentage, the more sensitive the model is to the considered parameter) for the $f_{s} P(\mathrm{~A}), f_{s} S(\mathrm{~B})$ and $m l r(\mathrm{C})$ output variables calculated from logistic regression for $f_{s} P$ and $f s S$ and ANOVA for $m l r$ with the D-Optimal experimental design (theta and lambda correspond to the parameters $\theta$ and $\lambda$ of the reproduction process respectively).

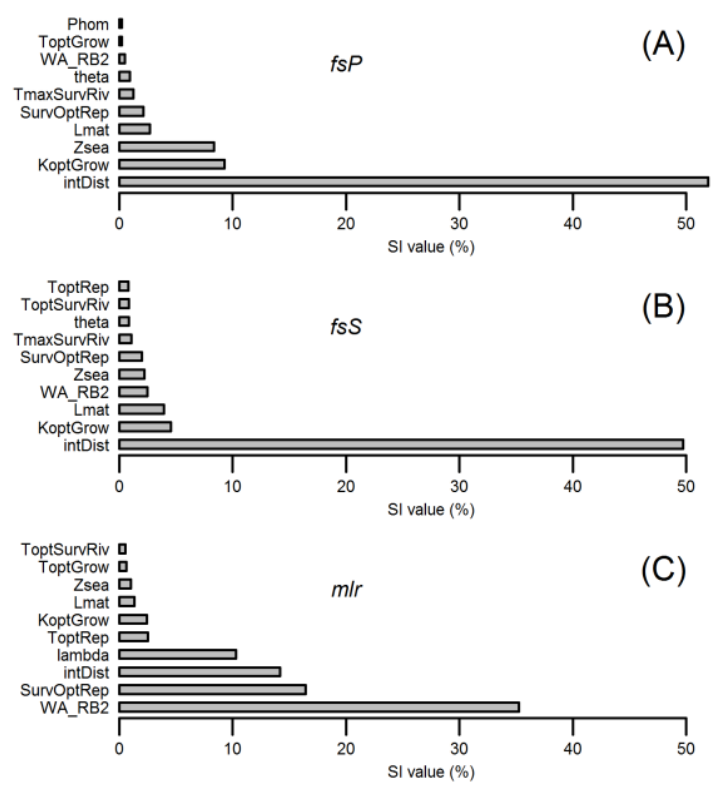


Fig. 4. TSI values (in \%; the higher the percentage, the more sensitive the model is to the considered parameter) for the $f_{s} P(\mathrm{~A}), . f s S(\mathrm{~B})$ and $m l r(\mathrm{C})$ output variables calculated from logistic regression on $f_{s} P$ and $f_{s} S$ and ANOVA on $m l r$ with the complete sampling design (theta, lambda, weightDB correspond to the parameters $\theta, \lambda$ and $w^{\text {deathBasin }}$ respectively).

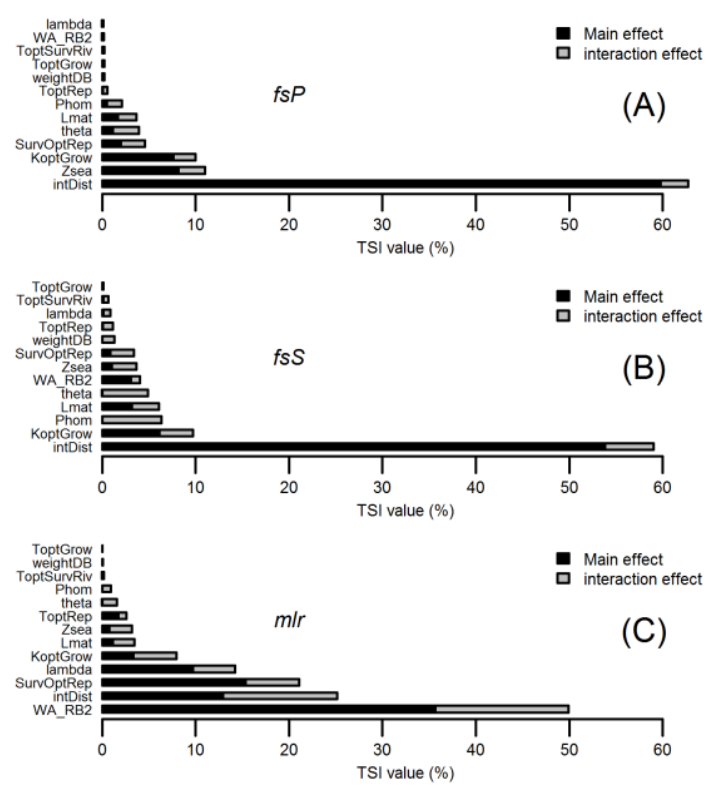

